\title{
RONALDO ARKADER
}

Concentrações de adrenomedulina e relações com o eixo

hipófise-adrenal e o controle glicêmico de crianças

submetidas à cirurgia cardíaca com circulação

extracorpórea

Tese apresentada à Faculdade de Medicina da Universidade de São Paulo para Obtenção do Título de Doutor em Ciências

Programa de Pós-Graduação Senso Estrito em Pediatria

Orientador: Profa Dra Thelma Suely Okay

São Paulo

2008 
Dados Internacionais de Catalogação na Publicação (CIP)

Preparada pela Biblioteca da

Faculdade de Medicina da Universidade de São Paulo

Creprodução autorizada pelo autor

\section{Arkader, Ronaldo}

Concentrações de adrenomedulina e relações com o eixo hipófise-adrenal e o controle glicêmico de crianças submetidas à cirurgia cardíaca com circulação extracorpórea / Ronaldo Arkader. -- São Paulo, 2008.

Tese(doutorado)--Faculdade de Medicina da Universidade de São Paulo. Departamento de Pediatria.

Área de concentração: Pediatria.

Orientadora: Thelma Suely Okay.

Descritores: 1.Adrenomedulina 2.Circulação extracorpórea 3.Insulina 4.Criança 5.Sistema hipófise-supra-renal

USP/FM/SBD-371/08 
À Luciana, minha esposa, pelo amor incondicional, dedicação, equilíbrio e paciência.

Aos meus filhos amados Bruno e Fernanda, motivo da nossa existência e justificativa por todos os esforços.

Aos meus pais, Rosalvo e Dora por tudo que fizeram para minha formação, ao meu irmão Rodrigo pela força.

A minha sogritcha Beatriz pelo carinho, compreensão e por todo incentivo e apoio ao longo desta jornada.

Ao meu sogro Isac pelo apoio e palavras sábias.

À minha orientadora, exemplo de dedicação e que ao longo desses anos me permitiu reconhecer as melhores qualidades de um pesquisador: ética e determinação. Obrigado pela confiança e por estar ao meu lado. 


\section{Agradecimentos}

A todos profissionais do Laboratório de Investigação Médica LIM/36 do Departamento de Pediatria da FMUSP: Gilda Maria Barbaro Del $\mathcal{N}$ egro, Lidia Yamamoto, Roberto Raiz Junior (que estará sempre conosco), Maria Luisa Nunes e Karina Hatamoto Kawasato que sempre me trataram com muito carinho e atenção.

Ao Dr Luiz Marcelo Sá Malbouisson pela paciência e exemplo.

Ao Prof Dr Werther Brunow de Carvalho pelo incentivo diário, e por me aprimorar na arte da Terapia Intensiva.

Ao Dr Mario Hirschheimmer pelos conselhos fraternos e pela confiança.

Ao Prof Dr Eduardo Juan Troster, pela sabedoria e humildade passada ao longo desses anos.

Ao Prof Dr Durval Damiani por ser exemplo a todos dentro da Endocrinologia Pediátrica.

Ao Dr Arthur Delgado pelas palavras de estímulo e pelo exemplo de dedicação.

A todos os médicos assistentes e residentes, enfermeiras $e$ auxiliares do INCOR pelo auxílio na etapa de coleta de material biológico.

A Dra. Solange Coppola Gimenez pelo direto auxílio na coleta dos pacientes. 
A Denize Terezinha Costa, Solange Rebolo Bastieri Serodio e Adriana Trindade Bezerra pelas orientações recebidas nas secretarias da Pós-Graduação e da Comissão de Pesquisa e Ética do Departamento de Pediatria da FMUSP.

A Mariza Kazue Yoshikawa, da Biblioteca do Instituto da Criança pelas orientações para a elaboração do manuscrito de acordo com as normas da Instituição.

Ao casal Milene e Nivaldo Rocha pela força e pelo auxílio na reprodução dos artigos científicos necessários à elaboração da tese e cópias das mesmas.

Ao Instituto Fleury por ter nos auxiliado nas dosagens de ACTH .

À Fundação de Amparo à Pesquisa do Estado de São Paulo, pelo auxílio financeiro (protocolo FAPESP $n^{o}$ 06/59214-6), fundamental para a compra dos kits e material utilizado para a pesquisa. 
"Cada pessoa que passa em nossa vida, passa sozinha, é porque cada pessoa é única e nenhuma substitui a outra. Cada pessoa que passa em nossa vida passa sozinha, e não nos deixa só, porque deixa um pouco de si e leva um pouquinho de nós. Essa é a mais bela responsabilidade da vida e a prova de que as pessoas não se encontram por acaso". 


\section{Sumário}

LISTA DE FIGURAS

LISTA DE TABELAS

LISTA DE SIGLAS E ABREVIATURAS

RESUMO

SUMMARY

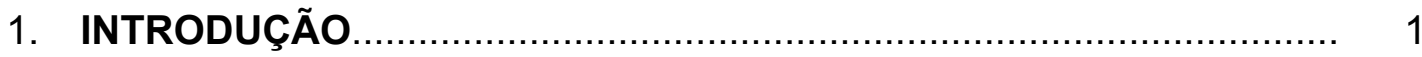

1.1. Resposta Inflamatória Sistêmica.............................................. 2

1.2. Circulação Extracorpórea como modelo de Resposta Inflamatória Sistêmica............................................................................... 3

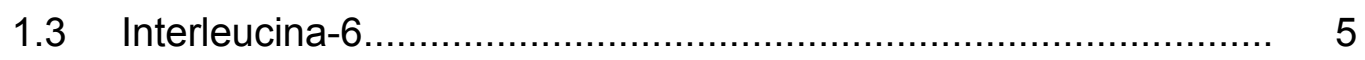

1.4. Glicose plasmática, Insulina e Peptídeo-C................................ 7

1.5. Cortisol e ACTH.............................................................. 10

1.6. Nomedulina ........................................................................ 11

2. JUSTIFICATIVA DO ESTUDO.......................................................... 15

3. HIPÓTESE DE TRABALHO........................................................... 17

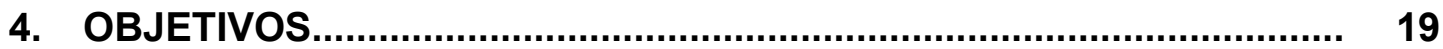

5. CASUÍSTICA .................................................................................. 21

6. CRITÉRIOS DE EXCLUSÃO........................................................... 24

7. MATERIAL E MÉTODOS................................................................... 26

7.1. Coleta.......................................................................... 27

7.2. Circulação Extracorpórea (CEC) .......................................... 28

7.3. Metodologia laboratorial específica...................................... 31

7.3.1. Glicose plasmática (laboratório Central do INCOR)............... 31 
7.3.2. Insulina e cortisol (Seção de Laboratório do Instituto da

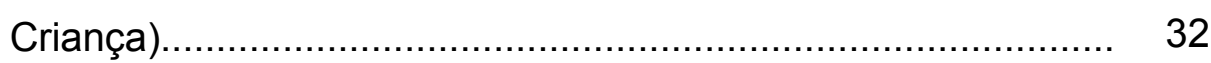

7.3.3. Adrenomedulina (LIM/36) .............................................. 33

7.3.4. Interleucina-6 (LIM/36) ................................................ 34

7.3.5. ACTH (Laboratório Fleury)............................................ 35

7.3.6. Peptídeo-C (Laboratório CRIESP) .................................... 37

8. ANÁLISE ESTATÍSTICA ............................................................ 39

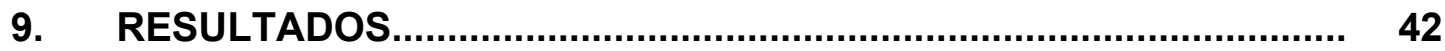

9.1. Cinética do ACTH e do cortisol......................................... 45

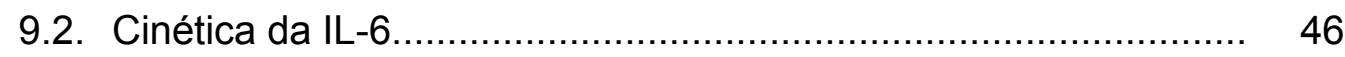

9.3. Cinética da glicemia, insulina e peptídeo C........................... 47

9.4. Cinética da adrenomedulina................................................ 51

10. DISCUSSÃO............................................................................. 57

11. CONCLUSÕES........................................................................ 66

12.. REFERÊNCIAS BIBLIOGRÁFICAS........................................... 68

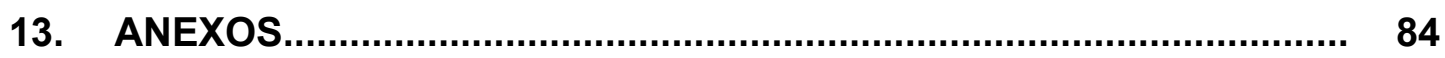




\section{Lista de Figuras}

PG

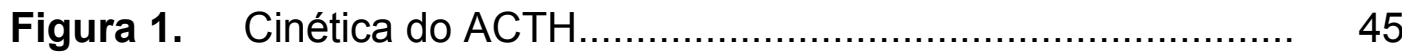

Figura 2. Cinética do cortisol.............................................. 46

Figura 3. Cinética da IL-6 ................................................ 47

Figura 4. Cinética glicêmica.................................................. 49

Figura 5. Cinética da insulina................................................ 50

Figura 6. Cinética do peptídeo-C.............................................. 50

Figura 7. Cinética da adrenomedulina...................................... 52

Figura 8. Correlação entre a adrenomedulina e peptídeo-C pós-

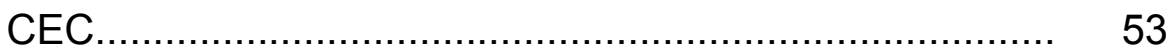

Figura 9. Correlação entre a adrenomedulina e peptídeo-C no $1^{\circ} \mathrm{PO}$

Figura 10. Proporção de pacientes que apresentaram redução do peptídeo-C do tempo pós-CEC para o $1^{\circ} \mathrm{PO} \mathrm{com}$ elevação da adrenomedulina..

Figura 11. Proporção de pacientes que apresentaram elevação da glicemia do tempo pós-CEC para o $1^{\circ} \mathrm{PO}$ com elevação da adrenomedulina. 


\section{Lista de Tabelas}

PG

Tabela 1. Dados demográficos dos pacientes................................. 44

Tabela 2. Mediana (percentil 25 e 75) das concentrações de insulina e peptídeo-C nos tempos do estudo.

Tabela 3. Valores de adrenomedulina nos tempos do estudo.......... 52 
ACCP/SCCM American College of Chest Physicians / Society of Critical Care Medicine.

ACTH Hormônio adrenocorticotrófico.

AM Adrenomedulina

CAPPesq Comissão de Análise de Projetos de Pesquisa do HCFMUSP

CEC Circulação Extracorpórea.

CPB Cardiopulmonary Bypass

CPE Comissão de Pesquisa e Ética

FMUSP Faculdade de Medicina da Universidade de São Paulo

${ }^{0} \mathrm{C}$

graus Celsius

$\mathrm{h}$

hora

$\mathrm{HC}$

Hospital das Clínicas da FMUSP

IL-1-

Interleucina 1

IL- 6

interleucina 6

IL- 8

Interleucina 8

INCOR

Instituto do Coração do HC/FMUSP.

$\mathrm{Kg}$

quilo

$\mathrm{L}$

litro

$\mathrm{mg}$

miligramas

$\mathrm{mL}$

mililitro

ng

nanogramas

pg

picogramas

$1^{\circ} \mathrm{PO}$

primeiro dia do pós-operatório

$2^{\circ} \mathrm{PO}$

segundo dia do pós-operatório

$3^{\circ} \mathrm{PO}$

terceiro dia do pós-operatório

SRIS

Síndrome da Resposta Inflamatória Sistêmica

TNF- $\alpha$

Fator de Necrose Tumoral alfa

USP

Universidade de São Paulo 


\section{Resumo}

Arkader, R. - Concentrações de adrenomedulina e relações com o eixo hipófise-adrenal e o controle glicêmico de crianças submetidas à cirurgia cardíaca com circulação extracorpórea. São Paulo, 2008. Tese (doutorado) Faculdade de Medicina da Universidade de São Paulo

Introdução: Adrenomedulina, peptídeo recentemente identificado, atua como mediador em diversos estados fisiológicos e patológicos, sendo expresso em inúmeros tecidos. Níveis elevados de adrenomedulina foram observados em quadros inflamatórios e sépticos, além de atividade inibitória da adrenomedulina sobre a liberação de insulina, o que poderia contribuir para a gênese e manutenção dos quadros hipeglicêmicos, situação comum em pacientes pediátricos internados em unidades de terapia intensiva, tendo sido comprovado que o controle glicêmico melhora o prognóstico nesses pacientes. O objetivo do estudo foi relacionar as concentrações de adrenomedulina com alterações de hormônios do eixo hipófise-adrenal e o controle glicêmico de crianças submetidas à cirurgia cardíaca com circulação extracorpórea (CEC) representando modelo de síndrome da resposta inflamatória sistêmica.

Material e métodos: Foram incluídas 20 crianças com idade entre 11-84 meses submetidas à cirurgia cardíaca com CEC. Foram avaliadas concentrações sangüíneas de glicose, insulina, peptídeo-C, cortisol, ACTH, interleucina- 6 e adrenomedulina nos tempos pré-CEC, pós-CEC, $1^{\circ} \mathrm{PO}$, $2^{\circ} \mathrm{PO}$ e $3^{\circ} \mathrm{PO}$. Os resultados foram expressos em medianas e inter-quartis. Todas crianças receberam antibioticoterapia profilática (Cefuroxima $150 \mathrm{mg} / \mathrm{kg}$ ) e metilprednisolona $(30 \mathrm{mg} / \mathrm{kg}$ ) na indução anestésica.

Resultados: Adrenomedulina aumentou de $1,13 \mathrm{ng} / \mathrm{mL}(0.83-1.81)$ préCEC a $3,28 \mathrm{ng} / \mathrm{mL}(1.82-4.25)$ no $1^{\circ} \mathrm{PO}(\mathrm{p}=0,0005)$. A insulina e $\mathrm{O}$ peptídeo-C apresentaram queda do tempo pré-CEC ao $1^{\circ} \mathrm{PO}: 10,9 \mu \mathrm{U} / \mathrm{mL}$ $(10.5$ - 13.6) a $2,88 \mu \mathrm{U} / \mathrm{mL}(1.68-3.46)(p=0,0001)$ e $1,44(0.93-2.08)$ a 
$0.89 \mathrm{ng} / \mathrm{mL}(0.58-2.06)(\mathrm{p}=0,076)$, respectivamente. Houve aumento da glicemia de 86,5 mg/dL (67 - 88) pré-CEC a $169 \mathrm{mg} / \mathrm{dL}\left(153\right.$ - 201) no $1^{\circ} \mathrm{PO}$ $(p=0,0001)$. Não houve alterações significativas das concentrações de cortisol e ACTH. Após a CEC todas as concentrações de interleucina-6 encontravam-se elevadas retornando aos valores normais no $3^{\circ} \mathrm{PO}$. Houve correlação negativa entre as concentrações de peptídeo-C e de adrenomedulina no $1^{\circ} \mathrm{PO}(R=-0,70-p<0,0009)$.

Conclusão: os resultados deste estudo indicam que a adrenomedulina possa ter contribuído para a gênese e manutenção da hiperglicemia em pacientes pediátricos com SRIS, agindo por intermédio da redução das concentrações de insulina e do peptídeo-C. 


\section{Summary}

Arkader, R.- Adrenomedullin concentration and relationship with pituitayadrenal axis and glicemic control in children after cardiopulmonary bypass. São Paulo, 2008. (Thesis) - Faculdade de Medicina da Universidade de São Paulo

Background: Adrenomedullin (AM), a recently identified vasoactive peptide, is expressed in a large number of tissues and was found to be increased in some pathophysiologic conditions such as sepsis and Systemic Inflammatory Response Syndrome (SIRS). It has been shown that AM inhibits insulin secretion by means of a direct action on pancreatic $\beta$-cells thus contributing to the genesis and sustaining of hypeglicemia, a common condition in critically ill pediatric patients. Therefore, the strict control of glucose concentrations has proved beneficial and associated to decrement of morbimortality rates in adults and children. The aim of the present study was to monitor serum adrenomedullin concentration in parallel with interleukin-6, plasma glucose, insulin and C-peptide, as well as ACTH and cortisol in pediatric patients submitted to cardiac surgery and cardiopulmonary bypass (CPB) representing a SIRS model.

Methods: Twenty children aged 11-84 months who underwent cardiac surgery requiring cardiopulmonary bypass were prospective studied. Blood glucose, insulin, C-peptide, adrenocorticotropic hormone, cortisol, interleukin6 and $A M$ were measured immediately before cardiopulmonary bypass (BCPB), immediately after CPB, on the first (POD1), second (POD2) and third days (POD3) after surgery. Data were expressed by median values and inter quartile range. All children received profilatic antibiotic (cefuroxime $150 \mathrm{mg} / \mathrm{kg}$ ) and methylprednisolone $(30 \mathrm{mg} / \mathrm{kg}$ ) during induction of anesthesia.

Results: Adrenomedullin increased from $1.13 \mathrm{ng} / \mathrm{mL}(0.83-1.81) \mathrm{BCPB}$ to $3.28 \mathrm{ng} / \mathrm{mL}(1.82-4.25)$ in POD1 ( $p=0.0005)$. Insulin dropped from 10.9 $\mu \mathrm{U} / \mathrm{mL}(10.5-13.6)$ BCPB to $2.88 \mu \mathrm{U} / \mathrm{mL}(1.68-3.46)$ in POD1 $(p=0.0000)$. 
C-peptide decreased from $1.44(0.93-2.08)$ BCPB to $0.89 \mathrm{ng} / \mathrm{mL}(0.58-$ $2.06)$ in POD1 $(p=0.076)$. Glucose increased from $86.5 \mathrm{mg} / \mathrm{dL}(67-88)$ $B C P B$ to $169 \mathrm{mg} / \mathrm{dL}(153-201)$ in POD1 ( $p=0.0000)$. No significant changes were observed in ACTH and cortisol levels. After CPB, IL-6 concentrations of all patients were significantly increased and returned to basal values in POD3 $(p=0.0009)$. There was a negative correlation between $C$-peptide an adrenomedullin in POD1 $(R=-0.70-p<0.0009)$.

Conclusion: Our results indicate that adrenomedullin might be partly responsible for the genesis and sustaining of hyperglycemia in pediatric SIRS patients, by means of the decrement of insulin and C- peptide levels. 
1 INTRODUÇÃO 


\section{INTRODUÇÃO}

\subsection{Resposta Inflamatória Sistêmica}

Síndrome da resposta inflamatória sistêmica (SRIS) é considerada modelo para o estudo da resposta hipercatabólica do organismo, sendo caracterizada por aumento do consumo de oxigênio, maior captação de glicose periférica, aumento da neoglicogênese, glicólise, com conseqüente hiperlactatemia ${ }^{1,2}$. Esse processo descrito como "auto-canibalismo" pode ser atribuído, ao menos parcialmente, à adaptação do eixo hipofisário ao quadro de resposta inflamatória sistêmica ${ }^{3,4}$.

Estados inflamatórios agudos tais como sepse, grandes queimaduras, politraumatismos e trauma cirúrgico são caracterizados pela presença de resposta inicial do organismo, com produção e liberação de citocinas pró-inflamatórias tais como o fator de necrose tumoral alfa (TNF- $\alpha$ ), a interleucina-1 (IL-1), a interleucina-6 (IL-6), e ainda, liberação de hormônios contra-reguladores como o adrenocorticotrófico (ACTH), as catecolaminas, o hormônio do crescimento $(\mathrm{GH})$ e o cortisol, ocorrendo supressão inicial da liberação de insulina, seguida de rápida elevação da mesma ${ }^{5,6}$. As citocinas associadas à liberação de hormônios induzem 
ativação de múltiplas vias metabólicas nas células musculares, nos adipócitos e nos hepatócitos, com conseqüente neoglicogênese, proteólise e lipólise caracterizando a instalação de estado hipercatabólico que culmina com o fornecimento de substratos vitais ao funcionamento de certos órgãos e também do sistema imunológico. O principal destes substratos é a glicose $e^{7}$

\subsection{Circulação Extracorpórea como modelo de Resposta Inflamatória Sistêmica}

Durante a circulação extracorpórea (CEC), vários processos que ocorrem simultaneamente determinam o aparecimento de reação inflamatória mais exacerbada, a saber: contato sangüíneo com as superfícies sintéticas do equipamento; períodos de isquemia e re-perfusão; parada circulatória total; hipotensão com fluxo não pulsátil; distúrbios de coagulação; endotoxemia ${ }^{8-10}$. Em conjunto, esses fatores desencadeiam complexa resposta inflamatória que inclui ativação das vias do complemento, liberação de citocinas, ativação de leucócitos e expressão de moléculas de adesão, produção de várias substâncias biologicamente ativas tais como endotelina, radicais livres, óxido nítrico, fator de agregação plaquetária e metabólitos do ácido araquidônico. Esta cascata inflamatória pode provocar disfunção orgânica temporária determinando instalação da síndrome da resposta inflamatória sistêmica (SRIS) ${ }^{8,10,11}$. 
A CEC em crianças apresenta particularidades ${ }^{12}$, e para tanto, circuitos e perfusatos foram aprimorados para o atendimento específico de pacientes pediátricos. Oxigenadores foram adaptados para o peso do paciente, assim como as canulações venosas e arteriais. Durante a CEC, o fluxo do perfusato e a temperatura devem ser rigorosamente controlados, pois são diretamente responsáveis pelas alterações endócrinometabólicas $^{13,14}$. O fluxo arterial não pulsátil é diretamente responsável pelo aumento da secreção de ACTH em crianças $^{13}$. Além disso, quanto menor a temperatura, mais acentuadas serão as alterações produzidas. Uma das alterações metabólicas mais importantes é a hiperglicemia ${ }^{15,}{ }^{16}$. Outras alterações endócrino-metabólicas podem ser desencadeadas diretamente pela CEC ou por mediadores liberados durante a $\mathrm{CEC}^{17,}{ }^{18}$. Urban et $\mathrm{al}^{19}$, descreveram a ligação da insulina ao circuito da circulação extracorpórea. 0 tempo de CEC parece exercer influência direta na morbi-mortalidade de crianças. Ridgen et al. em estudo prospectivo com 456 crianças submetidas à cirurgia cardíaca com CEC encontrou maior taxa de insuficiência renal aguda (IRA) dialítica e de mortalidade nos pacientes com tempo de CEC acima de 90 minutos. Do total de 24 crianças com IRA, 19 apresentaram tempo de CEC elevado, com quase $50 \%$ de óbitos $(8 / 19)^{20}$.

A utilização de corticóide previamente à CEC tem por objetivo a minimização dos efeitos sistêmicos causados pela circulação extracorpórea com redução das concentrações de marcadores inflamatórios ${ }^{10,}{ }^{21}$. No entanto, revisão sistemática recente comparou crianças que utilizaram corticóide pré-CEC com placebo, não tendo sido encontradas diferenças em 
relação à média de permanência em Unidade de Terapia Intensiva Pediátrica (UTIP), e ao tempo de ventilação pulmonar mecânica ${ }^{22}$. Estudo multicêntrico realizado em 36 serviços revelou ampla utilização de corticóide previamente a CEC na tentativa de minimizar seus efeitos, entretanto, o tempo, tipo de corticóide e a dose utilizada, variou muito entre os centros ${ }^{21}$. Em nosso meio, a utilização de corticóide (metilprednisolona) em crianças é comum $^{23,24}$. O succinato sódico de metilprednisolona na maior parte dos estudos é utilizado na indução anestésica aproximadamente duas horas antes do início da CEC, momento em que atinge seu pico de concentração sérica $^{21,25}$. A metabolização é essencialmente hepática com ênfase no papel da enzima 11-beta hidroxi-desidrogenase. Em indivíduos saudáveis a meiavida biológica pode chegar a 36 horas. Em nosso levantamento bibliográfico, não encontramos estudos sobre a farmacocinética da metilprednisolona em crianças submetidas à cirurgia cardíaca com circulação extracorpórea, apenas um artigo com pacientes adultos. Trabalhos em crianças submetidas à cirurgia cardíaca com CEC demonstraram redução de marcadores inflamatórios, principalmente a interleucina-6 (IL-6) com a utilização de metilprednisolona ${ }^{26,27}$.

\subsection{Interleucina-6}

A IL-6, polipeptídeo endógeno responsável pela sinalização entre células envolvidas na resposta imune e antiinflamatória, exerce papel chave 
na patogênese da resposta inflamatória sistêmica, sendo sintetizada por fagócitos mononucleares, fibroblastos, células endoteliais de vasos e células T, sendo responsável pela estimulação da produção hepática de proteínas de fase aguda, tais como a proteína C-reativa, além de aumentar a captação hepática de aminoácidos. A IL-6 tem sido utilizada como marcador da recuperação do organismo frente a estados hipercatabólicos, sendo sua produção inversamente proporcional a de albumina e de transferrina ${ }^{28-31}$. Injeção de endotoxina em adultos voluntários resultou em pico de IL-6 em duas horas ${ }^{32}$. As concentrações sangüíneas de IL-6 também vem sendo utilizadas como marcador de falência orgânica ${ }^{32}$.

Chew et al., em estudo prospectivo realizado em pacientes pediátricos submetidos à cirurgia cardíaca com CEC verificou elevação significativa da IL-6 após o procedimento ${ }^{33}$. Durante quadros de SRIS, a IL-6 favorece a liberação do fator liberador de corticotrofina (CRF), e do ACTH pela hipófise ${ }^{34-36}$. Esposito et al. ${ }^{37}$, sugeriram que picos de hiperglicemia poderiam induzir maior liberação de IL-6 por meio de mecanismos oxidativos, corroborando os achados de Tsigos et al., os quais verificaram elevação da glicemia após infusão de IL-6 recombinante em voluntários sadios $^{38}$. Pickup et al., demonstraram que concentrações aumentadas de IL6 estariam relacionadas à resistência insulínica em pacientes com diabetes mellitus do tipo 2 e síndrome metabólica ${ }^{39,}{ }^{40}$. Wasmuth et al., correlacionaram concentrações elevadas de IL-6 e hiperglicemia em 189 pacientes adultos admitidos em Unidades de Terapia Intensiva (UTI) ${ }^{41}$. 


\subsection{Glicose plasmática, Insulina e Peptídeo-C}

Como descrito anteriormente, inúmeras alterações fisiopatológicas podem co-existir durante e após a CEC. Nos últimos anos, após a demonstração de que o controle glicêmico rigoroso reduz a morbimortalidade de pacientes adultos no período pós-operatório (incluindo cirurgia cardíaca), este controle tem sido utilizado como marcador independente de prognóstico tanto nas unidades de terapia intensiva de pacientes adultos, quanto nas pediátricas ${ }^{42,43}$. Entretanto, até o momento, a fisiopatologia da hiperglicemia não está bem estabelecida principalmente nos pacientes em pós-operatório de cirurgia cardíaca com $\mathrm{CEC}^{44}$. Alguns autores apontam para a resistência insulínica, como causa da hiperglicemia, enquanto outros para a redução de insulina, porém existem vários fatores interferentes tais como o anestésico utilizado, presença ou não de hiperoxia, oferta inadequada de glicose no período intra-operatório ${ }^{15,42,45-47}$.

A insulina é formada por duas cadeias polipeptídicas: cadeia a (21 aminoácidos) e cadeia b (30 aminoácidos), sendo que os aminoácidos 63 e 31 unem a insulina ao peptídeo C. No complexo de Golgi existe um sistema enzimático que separa a insulina do peptídeo-C por meio de clivagem nos aminoácidos 63 e 31 . O principal sinal regulador para liberação de insulina é a concentração plasmática de glicose, ou seja, quando existe muita glicose circulante ocorre sinalização para as células beta das ilhotas de Langerhans do pâncreas no sentido de produzir e liberar mais insulina e peptídeo-C na circulação, em quantidades equimolares. Recentes estudos demonstram que 
o processo de exocitose para a secreção insulínica é heterogêneo, com liberação rápida ou lenta de insulina, e que a velocidade de liberação de insulina difere daquela do peptídeo-C. Recentemente, inúmeros trabalhos têm enfatizado a importância do peptídeo-C não só como marcador de reserva pancreática, mas também como peptídeo biologicamente ativo. Uma das principais ações do peptídeo C é a estimulação da enzima óxido nítrico sintetase com aumento subseqüente do óxido nítrico que é potente vasodilatador.

Na tentativa de elucidar a cinética glicêmica nos quadros de SRIS, alguns autores têm estudado o perfil da secreção insulínica em diversos tempos. Black et al descreveram aumento do clearance de insulina em pacientes politraumatizados ${ }^{48}$. Dahn et al $^{49}$ realizaram dosagens seriadas de insulina e peptídeo-C em três grupos diferentes de pacientes (controle, segundo pós-operatório cirúrgico sem intercorrências, e pacientes sépticos em pós-operatório). Foi realizado teste de tolerância à glicose (via endovenosa) nesses pacientes, sendo as glicemias encontradas, respectivamente: $108 \pm 15 ; 108 \pm 8$ e $99 \pm 25 \mathrm{mg} / \mathrm{dL}$. Após 15 minutos os níveis se elevaram para $302 \pm 30 ; 239 \pm 35$ e $243 \pm 42 \mathrm{mg} / \mathrm{dL}$, sendo os níveis de insulina correspondentes ao tempo basal de $16 \pm 8,4 ; 10 \pm 3,4$ e $9,5 \pm 4,4 \mu \mathrm{U} / \mathrm{mL}$, e após estímulo $51 \pm 14 ; 42,4 \pm 31$ e $20,4 \pm 6,8 \mu \mathrm{U} / \mathrm{mL}$. Os valores obtidos demonstram menor resposta insulínica nos pacientes com sepse, ou aumento do "turnover" de insulina, o que foi confirmado pela maior excreção urinária (em 24 horas) do peptídeo-C (com creatinina urinária e sangüínea normais). É importante relembrarmos que a insulina apresenta 
meia-vida curta (3 a 5 minutos) com extração hepática elevada (60 a 80\%), enquanto o peptídeo-C possui meia-vida mais longa (30 minutos), não sofrendo extração hepática, e sendo eliminado pelos rins. Recentes trabalhos em pós-operatório de cirurgia cardíaca com CEC têm demonstrado que o peptídeo-C, por ser mais estável, constituiria marcador mais fidedigno para o manejo do controle da hiperglicemia nesse grupo de pacientes.

Tanto a hiperglicemia, quanto a resistência insulínica parecem constituir alterações metabólicas comumente observadas em pacientes gravemente enfermos internados em unidades de terapia intensiva de adultos e pediátricas ${ }^{42}$. Os efeitos deletérios da hiperglicemia já foram descritos com relação à função neutrofílica e macrofágica, assim como na disfunção e degeneração axonal ${ }^{41,42}$. Em pacientes que foram submetidos à terapia insulínica contínua para manutenção de concentrações plasmáticas de glicose abaixo de $110 \mathrm{mg} / \mathrm{dL}$, observou-se redução do uso de antibióticos, além de efeitos antiinflamatórios, regulação da produção de óxido nítrico na microcirculação, menor número de transfusões de hemocomponentes, e prevenção de insuficiência renal aguda. A manutenção dos níveis glicêmicos abaixo de $110 \mathrm{mg} / \mathrm{dL}$ nesses pacientes (adultos) foi associada à significativa redução da morbi-mortalidade ${ }^{42}$.

Em crianças submetidas à cirurgia cardíaca já existia preocupação com o controle glicêmico desde o final da década de 60 , com descrição de alterações da insulinemia ${ }^{50,51}$. Bialkowski et al. em estudo prospectivo em crianças submetidas à cirurgia cardíaca com CEC demonstrou redução dos níveis de insulina ${ }^{15}$. Dandona et al, e Das et al, descreveram efeitos 
antiinflamatórios da insulina, corroborando estudos clínicos nos quais conclui-se que a utilização da mesma em infusão contínua poderia beneficiar os pacientes ${ }^{52-54}$. Evidências recentes indicam que a terapia insulínica poderia ser mais importante que o controle glicêmico propriamente dito para o prognóstico dos pacientes. Além disso, Gao et al., descreveram efeitos anti-apoptóticos da insulina após estímulos variados ${ }^{55,56}$, o que explica, ao menos em parte, os efeitos benéficos que a terapia insulínica parece produzir em pacientes com afecções que induzem hipercatabolismo.

A ocorrência de resistência insulínica em vigência de processos inflamatórios sistêmicos também foi observada em modelos animais, por intermédio da administração de endotoxinas e citocinas, causando redução da captação de glicose pela musculatura esquelética. No entanto, o mecanismo pelo qual citocinas induziriam resistência insulínica é ainda desconhecido ${ }^{57}$. Hotamisligil et al., demonstraram que o TNF- $\alpha$ age inibindo receptores insulínicos via fosforilação da tirosina que é mediada pela insulina, com conseqüente alteração dos transportadores na superfície das células $(\text { GLUT4) })^{58}$.

\subsection{Cortisol e ACTH}

O cortisol é produzido pelo córtex da glândula supra-renal ${ }^{3}$ após estímulo do hormônio adrenocorticotrófico hipofisário (ACTH). Exerce funções vitais na manutenção do tônus vascular, integridade endotelial, 
potencializando os efeitos das catecolaminas, e, juntamente com outros hormônios contra-reguladores, estaria envolvido na gênese da hiperglicemia ${ }^{59}$. Nos quadros sépticos, níveis circulantes de cortisol podem estar elevados quando comparados com indivíduos saudáveis ${ }^{59}$. Sam et al., demonstraram a existência de concentrações séricas elevadas de cortisol ( $\geq$ $1.242 \mathrm{mmol} / \mathrm{L}$, com intervalo de normalidade de 138-552 nmol/L), em pacientes com choque séptico que evoluíram a óbito, sem correlação com as concentrações plasmáticas elevadas de glicose ${ }^{60}$.

Pacientes submetidos a CEC apresentam estimulação do eixo hipotálamo-hipófise-adrenal com liberação final de cortisol. A utilização de corticóide sintético inibiria este eixo com redução dos níveis séricos de cortisol. Em 20 crianças submetidas à cirurgia cardíaca com CEC que utilizaram corticóide, Modan-Moses et al observaram que os níveis de cortisol plasmático endógeno se elevaram nas primeiras horas da cirurgia e retornaram a valores basais após 18-24 horas $^{61}$.

\subsection{Adrenomedulina}

Adrenomedulina humana (AM) foi descrita em 1993 em estudo no qual pesquisadores analisaram amostras de células extraídas de feocromocitoma, com a intenção de identificar novos peptídeos vasoativos ${ }^{62}$. Descreveram nova molécula com potente ação vasodilatadora, que atua dentro das células via ativação do AMP cíclico ${ }^{63}$, e possui meia-vida 
plasmática de $22 \pm 1,6$ minutos. A AM é composta por peptídeo de 52 aminoácidos $^{64}$, e codificada por gene localizado no braço curto do cromossomo 11 (11p1-3), expresso em vários tecidos ${ }^{65}$. Inicialmente, concentrações elevadas de AM foram observadas na medula adrenal, ventrículos, rins e pulmões. Posteriormente, descobriu-se que a AM é encontrada em concentrações elevadas nas células endoteliais, juntamente com o óxido nítrico (NO) e a endotelina ${ }^{65,66}$. Os valores considerados normais para a AM encontram-se entre 1 e 10 picomoles/L, com 95\% dos indivíduos apresentando concentrações entre 2 e 3,5 picomoles/L ${ }^{67}$, não havendo variação quanto a gênero ou idade ${ }^{67}$. Em 1999, Elasser et al. (1999), descreveram uma proteína específica ligada a AM (AMBP-1) que poderia potencializar seus efeitos ${ }^{68}$.

Parkes et al., em modelo experimental demonstraram redução das concentrações de cortisol e $A C T H$ após infusão de $A M^{69}$. Samson et al também descreveram efeitos inibitórios na liberação de $A C T H$ pela $A M^{70}$. Thomson et al demonstraram a síntese e secreção de AM pela linhagem de células adrenais (H295R), com provável estímulo da esteroidogênese ${ }^{71}$. Letizia et al, avaliaram as concentrações de AM em pacientes com síndrome de Cushing (14 pacientes com adenoma hipofisário, oito pacientes com tumor adrenal), e observaram que a AM se encontrava elevada em ambos os grupos quando comparados aos controles, entretanto, os pacientes com adenoma hipofisário apresentavam concentrações mais elevadas que os pacientes com tumores adrenais ${ }^{72}$. 
Vários estudos demonstraram liberação de AM após estímulo representado pelo aumento das concentrações de citocinas próinflamatórias ${ }^{73,74}$. Mulder et al., foram os primeiros autores a descreverem os efeitos inibitórios da AM sobre a secreção de insulina, efeito observado em ilhotas de Langerhans de pâncreas de $\operatorname{ratos}^{75}$. Martinez et al., demonstraram, em modelo in vitro, a ocorrência de secreção insulínica reduzida após estímulo da AM. Essa demonstração foi possível graças ao uso de anticorpos monoclonais anti-AM, demonstrando uma vez mais que este peptídeo inibe a liberação de insulina pelas células beta das ilhotas pancreáticas, e quando a $\mathrm{AM}$ é bloqueada por anticorpos monoclonais ocorre maior liberação de insulina ${ }^{76}$. Alguns anos mais tarde, Hayashi et al., descreveram os efeitos da hiperglicemia induzida pelo aumento da expressão da AM em tecido vascular ${ }^{77}$. A hipoglicemia induzida pela insulina foi utilizada para provocar a liberação de AM pela medula da adrenal. No entanto, enquanto as concentrações de epinefrina se elevaram 20 vezes, não houve aumento das concentrações de $A M^{78}$. Masada et al. utilizando modelo experimental, não observaram liberação de epinefrina após infusão de $A M^{79}$. Sekine et al concluíram que a adrenomedulina exerceria efeito inibitório sobre as células beta das ilhotas pancreáticas, agindo por intermédio do bloqueio do receptor $\mathrm{G}$ que regula a exocitose, sendo que este bloqueio poderia ser revertido com a utilização da toxina pertussis $(\mathrm{PTX})^{80}$.

O provável "mecanismo protetor da insulina" em pacientes sépticos ainda é desconhecido ${ }^{81}$. Sabe-se que a função fagocitária de neutrófilos 
encontra-se prejudicada em pacientes hiperglicêmicos, e após correção da glicemia há melhora da fagocitose de bactérias ${ }^{81}$, contribuindo para 0 combate ao processo infeccioso. Outro potencial mecanismo protetor envolveria os efeitos anti-apoptóticos da insulina ${ }^{56}$, ou ainda, efeitos diretamente relacionados ao fato da insulina melhorar o controle glicêmico 41. 


\section{JUSTIFICATIVA DO ESTUDO}

A hiperglicemia ocorre freqüentemente em pacientes com SRIS e está associada a maior morbi-mortalidade ${ }^{41,42}$. A manutenção da glicemia dentro da faixa de normalidade demonstrou estar relacionada à melhor prognóstico nestes pacientes ${ }^{42}$. Entretanto, o mecanismo fisiopatológico que propicia esta melhora permanece pouco conhecido. A adrenomedulina (AM) poderia fazer parte dos fatores envolvidos na gênese e manutenção da hiperglicemia por intermédio da inibição da liberação de insulina. O uso da insulina em pacientes pediátricos com SRIS e hiperglicemia, situação bastante freqüente na prática clínica, ainda constitui recurso pouco utilizado nas unidades de terapia intensiva pediátrica, justamente pela ausência de marcadores laboratoriais (além da glicose plasmática e insulina) que possam auxiliar o manejo dos episódios de hiperglicemia, sem que se corra o risco de produzir hipoglicemia grave nos pacientes. Até o presente, não existem estudos realizados em adultos ou em população pediátrica abordando o tema com o enfoque proposto. 


\section{HIPÓTESE DO TRABALHO}




\section{HIPÓTESE DO TRABALHO}

A elevação da adrenomedulina nos pacientes com SRIS inibe a produção de insulina, aumenta a liberação de $A C T H$, e seqüencialmente a de cortisol, contribuindo para a manutenção da hiperglicemia nesses pacientes. 
4 OBJETIVOS 


\section{OBJETIVOS}

Analisar as concentrações séricas de adrenomedulina em um grupo de pacientes pediátricos submetidos à cirurgia cardíaca com circulação extracorpórea e suas relações com o eixo-hipófise adrenal e o controle glicêmico. 


\section{CASUÍSTICA}

O presente estudo obteve a aprovação da Comissão de Pesquisa e Ética (CPE) do Instituto do Coração do HC/FMUSP, e da CAPPesq (Comissão para Análise de Projetos de Pesquisa do HC/FMUSP), tendo recebido o protocolo de número 675/05 de 9 de novembro de 2005 (anexo $5)$.

Grupo de estudo. A casuística foi composta por 20 pacientes pediátricos com SRIS, comprovadamente sem infecção, portadores de comunicação inter-atrial (CIA) ou inter-ventricular (CIV), de ambos os gêneros, na faixa etária de 13 meses até 18 anos, atendidos no Instituto do Coração do Hospital das Clínicas da Faculdade de Medicina da USP, e que tinham indicação médica de intervenção cirúrgica com circulação extracorpórea (CEC).

O grupo controle foi composto por 10 crianças com CIA ou CIV que tiveram amostras de sangue coletadas uma semana antes do procedimento cirúrgico, tendo sido avaliadas as concentrações de AM nesse grupo. Doze pacientes adultos saudáveis, doadores de banco de sangue tiveram 
amostras sangüíneas coletadas e avaliação das concentrações de AM (Tabela 2 Anexo 2 e 3 pg 85).

O fato de incluirmos desde lactentes jovens até adolescentes não deve ter influenciado a análise dos resultados de AM, uma vez que as concentrações deste hormônio não variam de acordo com o gênero e a idade ${ }^{67}$.

O número de pacientes a serem alocados no estudo foi definido com base na limitação orçamentária para a realização de todos os exames laboratoriais pretendidos, sendo que cada paciente teve cinco amostras de sangue coletadas para cada tipo de exame. Trata-se conseqüentemente de casuística de conveniência. Consultando a literatura foi possível verificar que estudos semelhantes (porém envolvendo menor número de marcadores e tempos de coleta) foram realizados com casuísticas ainda mais restritas. 


\section{CRITÉRIOS DE EXCLUSÃO}




\section{CRITÉRIOS DE EXCLUSAÕ}

Recém-nascidos e lactentes até 12 meses de idade foram excluídos da casuística devido à homeostase peculiar da glicose em recémnascidos, além da imaturidade do eixo hipófise-adrenal em recém-nascidos e lactentes jovens. Também foram excluídos todos os pacientes que poderiam apresentar resposta inflamatória anômala devido à presença de processos infecciosos, hepatopatias, endocrinopatias, nefropatias, doenças auto-imunes, hipertensão pulmonar, insuficiência cardíaca congestiva, uso de dopamina após admissão na UTIP, utilização de insulina exógena durante o estudo ou que estivessem sob corticoterapia. 
7 MATERIAL E MÉTODOS 


\section{MATERIAL E MÉTODOS}

\subsection{COLETA}

As coletas de sangue para a determinação das concentrações de adrenomedulina, glicose, insulina, peptídeo C, IL-6, cortisol e ACTH, foram realizadas no INCOR, após obtenção do consentimento dos pais ou responsáveis legais, e assinatura do Termo de Consentimento Livre e Esclarecido. Os procedimentos cirúrgicos foram realizados pelos mesmos cirurgiões (MJ e RSA).

Foram obtidos $6 \mathrm{~mL}$ de sangue em tubo de coleta sem aditivos, com gel separador (Becton Dickinson - BD), para a determinação das concentrações séricas de IL-6, insulina, peptídeo C, ACTH, cortisol e adrenomedulina, além de outros $2 \mathrm{~mL}$ de sangue em tubo com fluoreto de sódio (BD) para a determinação da glicose plasmática, em cada um dos cinco tempos de coleta. Tendo em vista que a glicose plasmática faz parte da avaliação laboratorial rotineira desses pacientes, o exame foi realizado no Laboratório Central do INCOR. Sendo assim, para a pesquisa propriamente dita foram obtidos $6 \mathrm{~mL}$, que após centrifugação, resultaram em 
aproximadamente $2,5 \mathrm{~mL}$ de soro, volume mínimo para permitir a realização dos seis exames laboratoriais pretendidos, em duplicata, como preconizam as metodologias que foram utilizadas, em especial a enzima imunoensaio EIA (IL-6 e AM), além do imunoensaio fluorimétrico (insulina, e cortisol), e em menor grau o EIA-quimioluminescente (ACTH). O Peptídeo-C foi realizado por imunoensaio de eletroquimioluminescência (ECLIA).

Os tempos de coleta foram os seguintes: imediatamente antes da circulação extracorpórea (pré-CEC); imediatamente após a circulação extracorpórea (pós-CEC); no primeiro dia do pós-operatório ( $\left.{ }^{\circ} \mathrm{PO}\right)$; no segundo dia do pós-operatório (2PO); no terceiro dia do pós-operatório ( $\left.3^{\circ} \mathrm{PO}\right)$. É importante salientar que no tempo pré-CEC os pacientes já se encontram com o tórax aberto, e em cirurgia há cerca de duas horas, não se tratando, portanto de avaliação pré-operatória (realizada em 10 crianças portadoras de CIA ou CIV em acompanhamento ambulatorial).

\subsection{Circulação Extracorpórea (CEC)}

Todos os pacientes foram avaliados quanto à existência de foco infeccioso antes do procedimento cirúrgico, e só foram admitidos àqueles nos quais todas as hemoculturas (e outras culturas, conforme o caso), foram negativas, além de não apresentarem sinais ou sintomas de infecção. Todos os pacientes receberam antibioticoterapia profilática com cefuroxima (150mg/kg), de acordo com o protocolo vigente no INCOR, além de 30 
$\mathrm{mg} / \mathrm{kg}$ de metilprednisolona após indução anestésica, na tentativa de minimizar os sintomas relacionados à SRIS, muito embora o corticóide possa contribuir para a elevação da glicemia. Ainda de acordo com normas vigentes no INCOR, todos os pacientes pediátricos receberam, desde o período pré-operatório imediato, soro de manutenção com volume de 40 $\mathrm{mL} / \mathrm{kg} /$ dia de solução glicosada a $10 \%$, o que corresponde a uma velocidade de infusão de glicose de $2,7 \mathrm{mg} / \mathrm{kg} /$ minuto. Posteriormente, os ajustes da infusão de glicose foram realizados de acordo com o controle das concentrações capilares de glicose (teste rápido realizado por meio de punção digital do paciente), com confirmações feitas em plasma caso a glicemia fosse $>110 \mathrm{mg} / \mathrm{dL}$ neste primeiro teste de triagem.

Os pacientes foram monitorizados conforme rotina do serviço. Durante a CEC, foi mantida temperatura corpórea entre 30 e $32^{\circ} \mathrm{C}$. As crianças foram submetidas à perfusão utilizando-se oxigenador de membrana modelo infantil, com fluxo não pulsátil gerado pelo sistema de roletes da bomba de CEC $\left(1,5 \mathrm{I} \cdot \mathrm{min}^{-1}\right)$. O perfusato (600 a $700 \mathrm{ml}$ de solução cristalóide) visou à manutenção de hematócrito superior a $30 \%$ por meio da administração de hemocomponentes quando necessário.

Todos os pacientes foram levados ao setor de recuperação pósanestésica infantil com fio de marca-passo epimiocárdico temporário e com dreno de mediastino e tórax (quando havia abertura de uma ou ambas as pleuras).

Todas as prescrições dos pacientes foram analisadas pelo pesquisador executante, com levantamento da dieta alimentar, além da 
composição dos soros de manutenção (para cálculo da velocidade de infusão de glicose), incluindo ainda a administração de fármacos que utilizassem solução glicosada. Este controle foi realizado diariamente, até o final da pesquisa, o que permitiu não apenas a determinação da velocidade de infusão de glicose diária de todos os pacientes, além do registro dos resultados de glicemia capilar e glicemia plasmática. Os pacientes foram mantidos na UTI pediátrica sob analgesia e sedação, em ventilação mecânica. O desmame foi realizado pela equipe de médica do INCOR com redução de pressões e concentrações de oxigênio de acordo com os resultados das gasometrias arteriais.

Os testes laboratoriais foram realizados no Laboratório Clínico do Instituto da Criança (insulina, cortisol), no Laboratório de Pediatria Clínica LIM/36 do Departamento de Pediatria da FMUSP (AM, IL-6), o ACTH, no setor de hormônios do Laboratório Fleury, e finalmente o peptídeo-C no Laboratório CRIESP. Os testes realizados no Laboratório Clínico já fazem parte da rotina assistencial dos pacientes da instituição, enquanto que a IL-6 e a adrenomedulina foram analisadas no Laboratório de Investigação Médica (LIM/36) do Departamento de Pediatria, com técnicas não rotineiras. As concentrações de ACTH foram determinadas pela metodologia utilizada atualmente no Laboratório Fleury (EIA-quimioluminescência). As dosagens de peptídeo-C foram realizados no Laboratório CRIESP, por meio de técnica de eletroquimioluminescência.

Imediatamente após a coleta, o material foi processado e armazenado até as respectivas dosagens. Cuidados na coleta e transporte 
imediato das amostras aos laboratórios constituem etapa crucial da pesquisa, e foram especialmente importantes para a determinação da concentração sérica de IL-6 (de maneira ideal as amostras de sangue devem ser prontamente processadas em centrífuga refrigerada, e as alíquotas de soro armazenadas em freezer $-86^{\circ} \mathrm{C}$, pelo fato das citocinas serem termolábeis), e plasmáticas do ACTH.

\subsection{Metodologia laboratorial específica}

\subsubsection{Glicose plasmática (laboratório Central do INCOR)}

Método da glicose hexoquinase (equipamento automatizado, Íntegra da Roche). A hexoquinase catalisa a fosforilação da glicose pelo ATP, dando origem à glicose-6-fosfato e ADP. A seguir, uma segunda enzima, a glicose6-fosfato desidrogenase (G6PDH) é utilizada para catalisar a oxidação da glicose-6-fosfato pelo $\mathrm{NAD+}$, dando origem ao NADH. A concentração de $\mathrm{NADH}$ formada é diretamente proporcional à concentração de glicose. É determinada medindo-se o aumento da absorbância no comprimento de onda de $340 \mathrm{~nm}$. O teste é capaz de detectar valores compreendidos entre 0-40 mmol/L (ou 0-720 mg/dL). O intervalo de referência para o teste em soro ou plasma (em jejum), de crianças e adultos é de: 3,05-6,38 mmol/L (ou $55-115 \mathrm{mg} / \mathrm{dL})^{82,83}$. O intervalo de normalidade para a glicemia de jejum é 
de 70 a $99 \mathrm{mg} / \mathrm{dL}$ para a definição de pré-diabetes e diabetes, enquanto que para os pacientes com SRIS admite-se glicemia de até $110 \mathrm{mg} / \mathrm{dL}^{42}$.

\subsubsection{Insulina e cortisol (Seção de Laboratório do Instituto da Criança)}

Imunoensaio fluorimétrico (equipamento automatizado, auto-Delphia da Perkin Elmer). Trata-se de imunoensaio fluorimétrico baseado na competição entre moléculas de cortisol marcadas com europium e as moléculas de cortisol livres presentes na amostra do paciente. As moléculas livres e ligadas competirão por número limitado de sítios de ligação, que são específicos para o cortisol, e que se encontram na superfície de anticorpos monoclonais biotinilados (produzidos em camundongos). $O$ uso da substância danazol e do ácido tricloroacético neutralizado em tampão facilita a liberação das moléculas de cortisol de proteínas que se ligam a elas. Conseqüentemente, o teste mede a quantidade total de cortisol presente na amostra. A seguir, uma superfície sólida recoberta por estreptavidina se liga ao anticorpo biotinilado, separando os anticorpos ligados dos anticorpos livres. Na próxima etapa, uma solução "enhancer" provocará a dissociação dos íons de europium que estão ligados ao cortisol para dentro da solução de reação, provocando liberação de fluorescência, que é então medida em cada um dos orifícios de teste. A fuorescência emitida é inversamente proporcional à concentração de cortisol presente na amostra de soro. 
Valores de referência (para amostras colhidas pela manhã): 201-681 nmol/L (ou 7,29 - 24,7 ug/dL). No caso da insulina, o princípio do teste é o mesmo, com a ressalva de que ao final, a fluorescência emitida em cada orifício é diretamente proporcional à concentração de insulina de cada amostra. Os valores de referência para a insulina são: 2,34-26,4 uU/mL (ou 14,0 - 158 $\mathrm{pmol} / \mathrm{L})^{84-86}$

\subsubsection{Adrenomedulina (LIM/36)}

Os ensaios foram realizados seguindo as instruções do fabricante do kit da "Phoenix Pharmaceuticals Inc. Belmont, CA, USA". Resumidamente, 200 microlitros de plasma, ou soro, de cada paciente, são previamente acidificados e extraídos em colunas de separação C18. A seguir, as amostras são adicionadas a orifícios da placa de microtitulação que foi sensibilizada com o anticorpo primário (anti-ADM). Após período de incubação e lavagens, é adicionado o anticorpo secundário que é biotinilado. Acrescenta-se então a solução de estreptavidina -peroxidase e realiza-se novo período de incubação. Após esta etapa, adiciona-se o substrato da enzima (peróxido de hidrogênio). A reação enzima-substrato é interrompida com a adição de solução $2 \mathrm{~N}$ de HCL. A leitura das absorbâncias é feita em leitor ELISA no comprimento de onda de $450 \mathrm{~nm}$. Para cada placa de microtitulação é necessário construir uma curva de calibração. Para tanto, amostras de plasma recebem concentrações crescentes e conhecidas do 
peptídeo (ADM), e são submetidas ao mesmo procedimento de extração ácida, com posterior análise, segundo o mesmo procedimento usado para as amostras dos pacientes ${ }^{87}$. Valores de referência recomendados pelo fabricante: até $0,5 \mathrm{ng} / \mathrm{ml}$.

\subsubsection{Interleucina-6 (LIM/36)}

EIA ("enzyme immuno assay") com kit da R\&D Systems (EUA). Trata-se de testes imunoenzimáticos quantitativos do tipo sanduíche. O kit da R\&D Systems fornece uma placa de microtitulação com 96 orifícios previamente sensibilizados com um anticorpo monoclonal especificamente dirigido contra a IL-6. Duzentos microlitros da amostra de soro do paciente (ou 200 microlitros de solução padrão com concentração conhecida, ou do controle do kit), são adicionados aos orifícios e a citocina presente na amostra ligar-se-á ao anticorpo imobilizado no fundo dos orifícios. Após 2 horas e meia de incubação em temperatura ambiente, e quatro lavagens que removem substâncias não ligadas, um anticorpo policlonal anti-citocina marcado com a enzima peroxidase é adicionado aos orifícios. Uma segunda incubação de 2 horas e meia em temperatura ambiente é seguida de mais quatro lavagens que também têm por objetivo a remoção de substâncias não ligadas. A próxima etapa consiste em adicionar o substrato da enzima (peróxido de hidrogênio) aos orifícios, e a substância cromogênica (tetramethylbenzidine ou TMB). A intensidade da cor observada em cada um 
dos orifícios será proporcional à quantidade de citocina que foi ligada na etapa inicial. A reação é interrompida com a adição da solução "STOP" ou seja, ácido sulfúrico $2 \mathrm{~N}$. As absorbâncias serão obtidas por espectrofotometria no comprimento de onda de $450 \mathrm{~nm}$, posteriormente corrigidas com leituras a 540 ou 570 nm (para a correção das distorções óticas causadas pelo poliestireno da placa de microtitulação). De acordo com o fabricante, o limiar de detecção do kit é de $0,70 \mathrm{pg} / \mathrm{mL}$. O normal é que o indivíduo tenha concentrações indetectáveis de IL-6, ou que cada estudo procure determinar seus valores de corte de acordo com características da população estudada.

\subsubsection{ACTH (Laboratório Fleury)}

O ACTH IMMULITE 2000 fase sólida é um ensaio do tipo enzimaimunoensaio quimioluminescente para ser utilizado no Analisador automatizado IMMULITE 2000, que é exatamente o equipamento que realiza o teste no Laboratório Fleury. Foi desenvolvido para a determinação quantitativa do hormônio adrenocorticotrófico (ACTH) em amostras de plasma obtidas após centrifugação de sangue total colhido em tubo com EDTA (BD), e armazenadas em congelador $-86^{\circ} \mathrm{C}$. Resumidamente, o princípio do teste é o seguinte: a pérola de poliestireno fase sólida é recoberta com anticorpo monoclonal murino específico para o ACTH. A amostra do paciente e a fosfatase alcalina conjugada ao ACTH são 
simultaneamente introduzidos no tubo de reação e incubados por 30 minutos a $37^{\circ} \mathrm{C}$ com agitação intermitente. Durante este período, o ACTH da amostra compete com a enzima marcada com ACTH por um número limitado de sítios ligantes do anticorpo da pérola. A enzima conjugada não ligada é removida por lavagem e centrifugação, o substrato é adicionado ao tubo de reação e incubado por mais 5 minutos. O substrato quimioluminescente, PPD (ester fosfato de adamantil dioxetano) é submetido à hidrólise em presença da fosfatase alcalina gerando um composto intermediário instável. A produção contínua deste intermediário resulta na emissão ininterrupta de luz. O complexo ligado, bem como sua emissão de fótons medidos pelo luminômetro, será inversamente proporcional à concentração de ACTH na amostra. O exame é realizado com 50 microlitros de amostra, a faixa de calibração varia de 12 a $1.250 \mathrm{pg} / \mathrm{mL}$ e a linearidade do teste atinge valores de até $1.250 \mathrm{pg} / \mathrm{mL}$. Acima deste valor a amostra será que ser re-testada com diluição. De acordo com o fabricante, o intervalo de normalidade pode variar de acordo com a população e os procedimentos em cada laboratório. O intervalo esperado varia de ND (não detectável) a 46 pg/mL (intervalo de confiança de 95\%). O teste não sofre interferência de icterícia ou hemólise, porém amostras lipêmicas podem necessitar de tratamento prévio (clareamento por ultracentrifugação). 


\subsubsection{Peptídeo-C (Laboratório CRIESP)}

As concentrações do peptídeo $\mathrm{C}$ foram realizadas em amostras de soro dos pacientes do grupo de estudo, bem como de algumas crianças com cardiopatia congênita em atendimento ambulatorial (representando os valores pré-cirúrgicos). Resumidamente, o imunoensaio de eletroquimioluminescência (ECLIA) foi desenvolvido para ser utilizado em analisadores de imunoensaio (Elecsys ou Cobas da Roche). Trata-se de técnica do tipo sanduíche, que utiliza 20 ul de soro ou plasma que são incubados em solução contendo um anticorpo monoclonal biotinilado específico anti-peptídeo-C, e um outro anticorpo monoclonal específico antipeptídeo $\mathrm{C}$ marcado com rutênio. Estes anticorpos reagem entre si formando um complexo do tipo sanduíche. Durante a segunda etapa da reação, após incorporação das micropartículas revestidas de estreptavidina, o complexo formado liga-se à fase sólida por meio de interação da biotina e da estreptavidina. A seguir, a mistura de reação é aspirada para a célula de leitura na qual as micropartículas são fixadas magneticamente à superfície do eletrodo. Os elementos não ligados são então removidos com ProCell. A aplicação de uma corrente elétrica ao eletrodo induz uma emissão quimioluminescente que é medida por um fotomultiplicador. Os resultados são determinados com base em curva de calibração gerada especificamente pelo analisador por intermédio de dois pontos além de uma curva principal incluída no código de barras do reagente. A precisão intra-ensaio do método é de 1,6 a 3,8\%, e a inter-ensaio de 1,7 a 4,0\%. Os valores de referência 
foram determinados em população de 96 homens e mulheres saudáveis (em jejum): de 1,1 a $4,4 \mathrm{ng} / \mathrm{ml}$ (ou $0,37-1,47 \mathrm{nmol} / \mathrm{l}$ ) representando os percentis 5 e 95 dos valores obtidos, tendo sido a mediana de $1,96 \mathrm{ng} / \mathrm{ml}$ ou $0,65 \mathrm{nmol} / \mathrm{l}$. 


\section{ANÁLISE ESTATÍSTICA}

Para a análise descritiva foram calculadas: média, desvio padrão, mínimo, mediana, máximo, freqüência e percentuais. Para comparar as medianas das concentrações de adrenomedulina por gênero (feminino ou masculino) e tipo de cirurgia foi utilizado o teste de Mann-Whitney. Para testar a associação das concentrações de adrenomedulina por idade e tempo de circulação extracorpórea foi utilizado o coeficiente de correlação de Spearman, assim como para correlacionar a adrenomedulina com os outros hormônios, em cada um dos tempos estudados.

Análise de Variância (ANOVA) para medidas repetidas com transformação por postos (ranks) foi utilizada para comparar as medidas entre os tempos. Quando a comparação entre tempos foi significativa, para verificar quais tempos diferiram, utilizou-se análise com dados emparelhados e correção para comparações múltiplas (Bonferroni).

Para comparar as concentrações dos hormônios com aquelas da adrenomedulina considerando o comportamento entre os tempos pré e pós CEC foram utilizados o Qui Quadrado e o teste Exato de Fisher. Para comparar as concentrações de hormônios com as da adrenomedulina 
considerando o comportamento entre os tempos pós-CEC e $1^{\circ} \mathrm{PO}$ foi utilizada a comparação de proporções (utilizando como referência percentual de $50 \%$ ). Foi considerado nível de significância de $5 \%$ (valor de $p \leq 0,05$ ). Os dados foram apresentados em mediana e percentis 25-75. Tabela Anexo 1 84. Todos os testes estatísticos estão disponíveis no Anexo pgs 87 à 95 . 
9 RESULTADOS 


\section{RESULTADOS}

A tabela 1 descreve as características dos pacientes submetidos à cirurgia cardíaca com CEC. Das vinte crianças do grupo de estudo, nove foram submetidas à cirurgia para correção de comunicação inter-ventricular (CIV) e 11 foram submetidas à cirurgia para correção de comunicação interatrial (CIA). Não foi realizada redução da infusão de glicose e/ou insulinoterapia nos pacientes deste estudo.

Não foram encontradas diferenças estatisticamente significantes quando os hormônios (insulina, peptídeo C, ACTH e cortisol) foram confrontados com o tipo de cirurgia, gênero, peso, idade, tempo de CEC e tempo de pinçamento aórtico (PA). 
Tabela 1. Dados demográficos dos 20 pacientes do estudo. $\mathrm{CIA}=$ comunicação inter-atrial, $\mathrm{CIV}=$ comunicação interventricular, CIVm= comunicação inter-ventricular membranosa, $\mathrm{CEC}=$ circulação extracorpórea, $\mathrm{PA}=$ pinçamento aórtico, $\mathrm{M}=$ masculino, $\mathrm{F}=$ feminino.

\begin{tabular}{|c|c|c|c|c|c|c|}
\hline \multirow[b]{2}{*}{ Pacientes } & \multirow[b]{2}{*}{ Tipo cirurgia } & \multirow[b]{2}{*}{ gênero } & \multirow{2}{*}{$\begin{array}{l}\text { Peso } \\
\text { (Kg) }\end{array}$} & \multicolumn{3}{|c|}{ CEC } \\
\hline & & & & $\begin{array}{c}\text { Idade } \\
\text { (meses) }\end{array}$ & (minutos) & $\begin{array}{c}\text { PA } \\
\text { (minutos) }\end{array}$ \\
\hline 1 & $\mathrm{CIA}$ & M & 18 & 56 & 54 & 30 \\
\hline 2 & $\mathrm{CIA}$ & M & 24 & 84 & 45 & 27 \\
\hline 3 & $\mathrm{CIA}$ & $\mathrm{F}$ & 10 & 29 & 37 & 23 \\
\hline 4 & $\mathrm{CIA}$ & $\mathrm{F}$ & 10 & 29 & 35 & 22 \\
\hline 5 & $\mathrm{ClA}$ & $\mathrm{F}$ & 11 & 30 & 45 & 21 \\
\hline 6 & $\mathrm{CIA}$ & $F$ & 12 & 31 & 42 & 16 \\
\hline 7 & CIVm & $\mathrm{F}$ & 12 & 32 & 72 & 25 \\
\hline 8 & CIV & $\mathrm{F}$ & 10 & 28 & 52 & 20 \\
\hline 9 & CIV & M & 16 & 48 & 60 & 30 \\
\hline 10 & $\mathrm{CIA}$ & M & 17 & 50 & 45 & 20 \\
\hline 11 & CIV & M & 15 & 43 & 67 & 26 \\
\hline 12 & $\mathrm{CIVm}$ & $\mathrm{F}$ & 16 & 52 & 84 & 35 \\
\hline 13 & CIV & $\mathrm{F}$ & 11 & 26 & 62 & 28 \\
\hline 14 & $\mathrm{CIA}$ & M & 18 & 48 & 50 & 20 \\
\hline 15 & $\mathrm{ClA}$ & M & 18 & 51 & 45 & 15 \\
\hline 16 & $\mathrm{CIA}$ & M & 11 & 30 & 55 & 35 \\
\hline 17 & CIV & $\mathrm{F}$ & 12 & 20 & 48 & 16 \\
\hline 18 & $\mathrm{CIA}$ & $\mathrm{F}$ & 14 & 38 & 65 & 35 \\
\hline 19 & $\mathrm{CIVm}$ & $\mathrm{M}$ & 15 & 38 & 77 & 23 \\
\hline 20 & CIV & $F$ & 10 & 11 & 42 & 15 \\
\hline
\end{tabular}

Todos os cálculos estatísticos, assim como as tabelas resultantes se encontram no Anexo 4. 


\subsection{Cinética do ACTH e do cortisol}

Não houve variações estatisticamente significantes das concentrações de ACTH (Figura 1) ou de cortisol (Figura 2) nos 20 pacientes incluídos no estudo, nos cinco tempos de coleta.

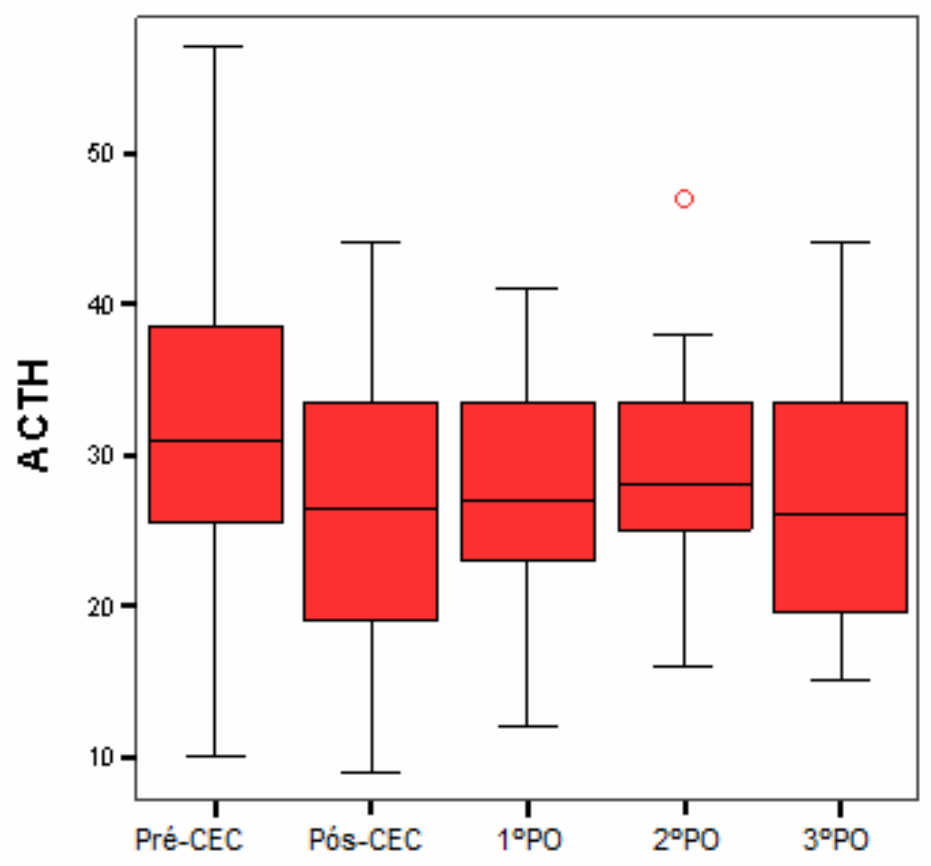

Figura 1. Cinética do ACTH (box-plot representando a mediana dos valores, percentis 25 e 75). Valores de referência até $46 \mathrm{pg} / \mathrm{ml}$. 


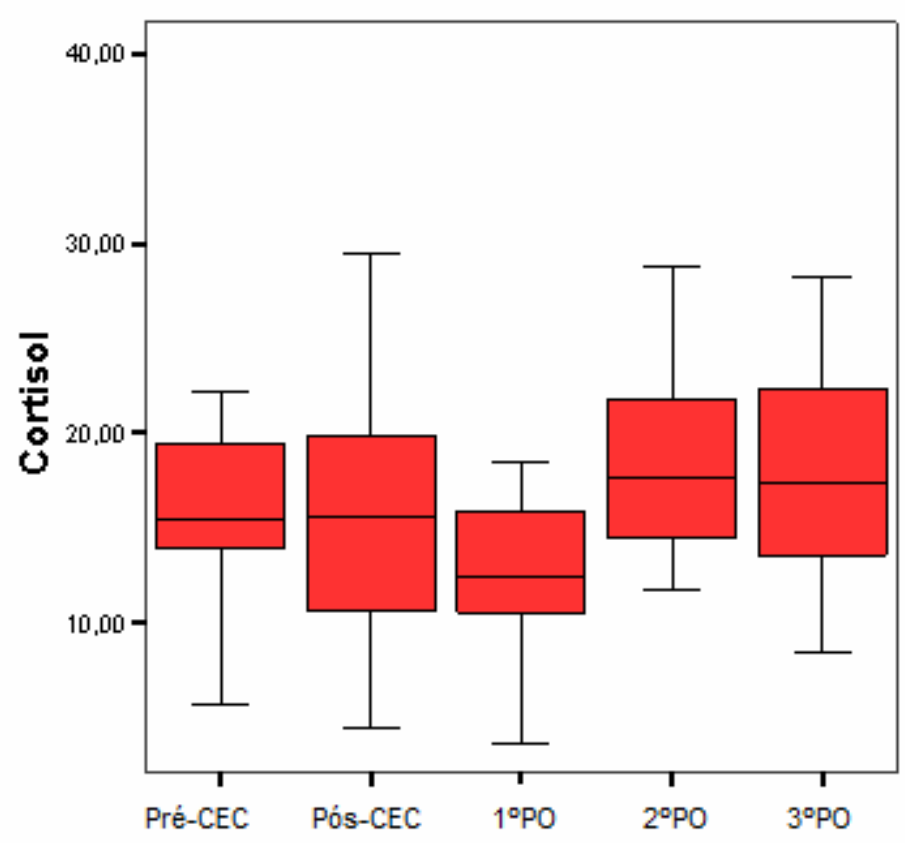

Figura 2. Cinética do cortisol. (box-plot representando a mediana dos valores, percentis 25 e 75). Valores de referência $7-25$ mcg/dl.

\subsection{Cinética da IL-6}

A IL-6 (Figura 3) encontrava-se elevada no pós-operatório de cirurgia cardíaca. O pico ocorreu no $1^{\circ} \mathrm{PO}$ com 14,21 de mediana (min. 13,2 - máx. 16,37) pg/ml para a IL-6. Foram encontradas diferenças estatisticamente significantes quando os valores pré-CEC foram comparados aos valores no $1^{\circ} \mathrm{PO}$ : mediana de $7,85(2,45$ - 12,65) versus $14,21(13,2$ $16,37) \mathrm{pg} / \mathrm{ml}(\mathrm{p}=0,0009)$. Houve diferença estatisticamente significante na comparação entre os tempos pós-CEC versus $3^{\circ} \mathrm{PO}(p=0,0001), 1^{\circ} \mathrm{PO}$ vesus $3^{\circ} \mathrm{PO}(p=0,0000), 2^{\circ} \mathrm{PO}$ versus $3^{\circ} \mathrm{PO}(p=0,0020)$ (Tabela / Anexo). 


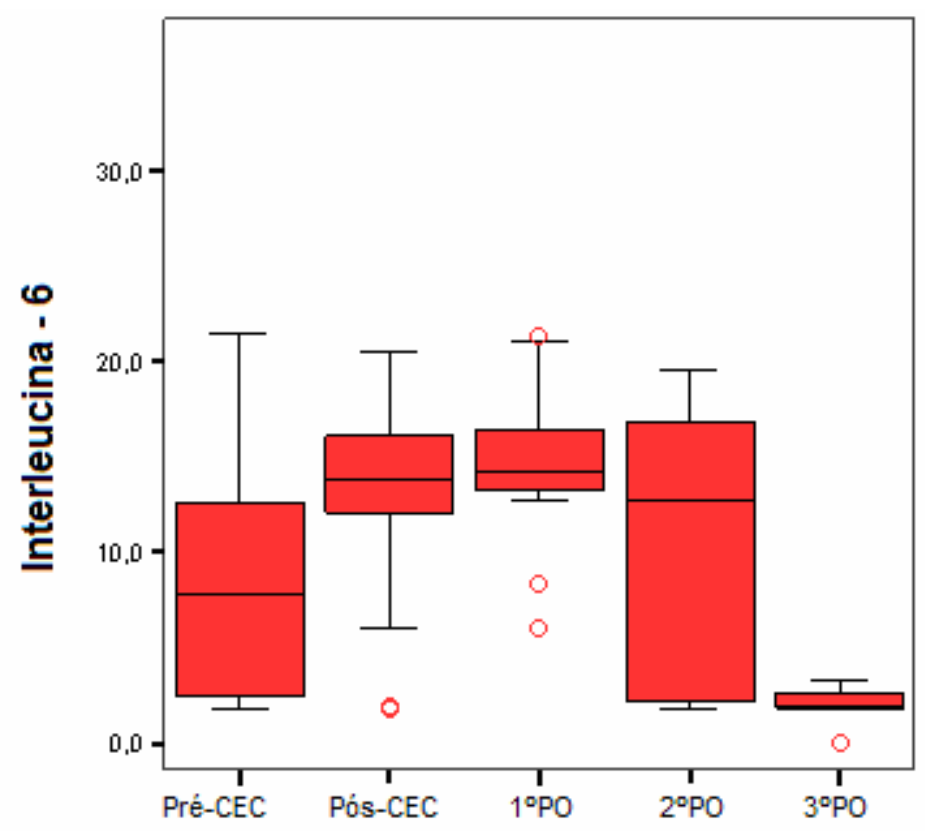

Figura 3. Cinética da IL-6. (box-plot representando a mediana dos valores, percentis 25 e 75). Valores de referência até $0,70 \mathrm{pg} / \mathrm{ml}$.

\subsection{Cinética da glicemia, insulina e peptídeo C}

No tempo pós-CEC houve aumento significativo nos níveis glicêmicos: mediana de 150,5 (min. 122,5 - máx. 163,5) mg/dL quando comparados aos valores pré-CEC $[86,5(67-88) \mathrm{mg} / \mathrm{dl}](\mathrm{p}=0,0000)$ como observado na Figura 4. As glicemias continuaram em ascensão até o $1^{\circ} \mathrm{PO}$ quando atingiram mediana de valores de 169 (min. 153,5 - máx. 201) mg/dL, sendo que a comparação entre os tempos pré-CEC $X 1^{\circ} \mathrm{PO}$ revelou diferenças estatisticamente significantes $(p=0,0000)$, retornando gradativamente aos valores basais no $3^{\circ} \mathrm{PO}$. (Tabela Anexo 4). 
As concentrações de insulina e do peptídeo-C, por outro lado, apresentaram comportamentos opostos ao da glicemia. No tempo pré-CEC a mediana dos valores do peptídeo-C e da insulina encontravam-se dentro dos limites da normalidade e nos tempos subseqüentes do estudo, houve redução progressiva dos níveis de insulina e peptídeo- $C$, atingindo o nadir de ambos os hormônios no $1^{\circ} \mathrm{PO}$ (Tabela 2, Figura 5 e Figura 6). No entanto, em termos estatísticos, apenas a mediana dos valores do peptídeoC encontrava-se abaixo dos limites da normalidade $(0,895)$, considerando valores de referência $1,1-4,4 \mathrm{ng} / \mathrm{ml}$ no $1^{\circ} \mathrm{PO}$, o que não ocorreu com a insulina que mesmo em queda manteve-se dentro da faixa de referência em todos os tempos de coleta (2 a $13 \mu U / L)$.

Tabela 2. Mediana (percentil 25 e 75) das concentrações de insulina e peptídeo-C nos tempos do estudo.

\begin{tabular}{|c|c|c|c|}
\hline & $\begin{array}{c}\text { Percentil } \\
25\end{array}$ & mediana & Percentil 75 \\
\hline Insulina pré-CEC & 10,5 & 10,905 & 13,605 \\
\hline Insulina pós-CEC & 1,6 & 3,19 & 5,265 \\
\hline Insulina $1^{\circ} \mathrm{PO}$ & 1,685 & 2,88 & 3,46 \\
\hline Insulina $2^{\circ} \mathrm{PO}$ & 3,045 & 5,14 & 9,04 \\
\hline Insulina $3^{\circ} \mathrm{PO}$ & 3,515 & 5,37 & 9,01 \\
\hline Peptídeo C pré-CEC & 0,93 & 1,445 & 2,085 \\
\hline Peptídeo C pós-CEC & 1,1 & 1,5 & 3,01 \\
\hline Peptídeo C $1^{\circ} \mathrm{PO}$ & 0,585 & 0,895 & 2,065 \\
\hline Peptídeo C $2^{\circ} \mathrm{PO}$ & 1,31 & 1,922 & 2,74 \\
\hline Peptídeo C $3^{\circ} \mathrm{PO}$ & 1,555 & 2,005 & 2,995 \\
\hline
\end{tabular}


Não obstante, houve diferença estatisticamente significante entre a mediana das concentrações de insulina do tempo pré-CEC versus todos os outros tempos, porém o mesmo não ocorreu com o peptídeo-C. Também houve diferença entre o $1^{\circ} \mathrm{PO}$ versus $2^{\circ} \mathrm{PO}(\mathrm{p}=0,0056)$ e $1^{\circ} \mathrm{PO}$ versus $3^{\circ} \mathrm{PO}$ $(p=0,0004)($ Tabela Anexo 1).

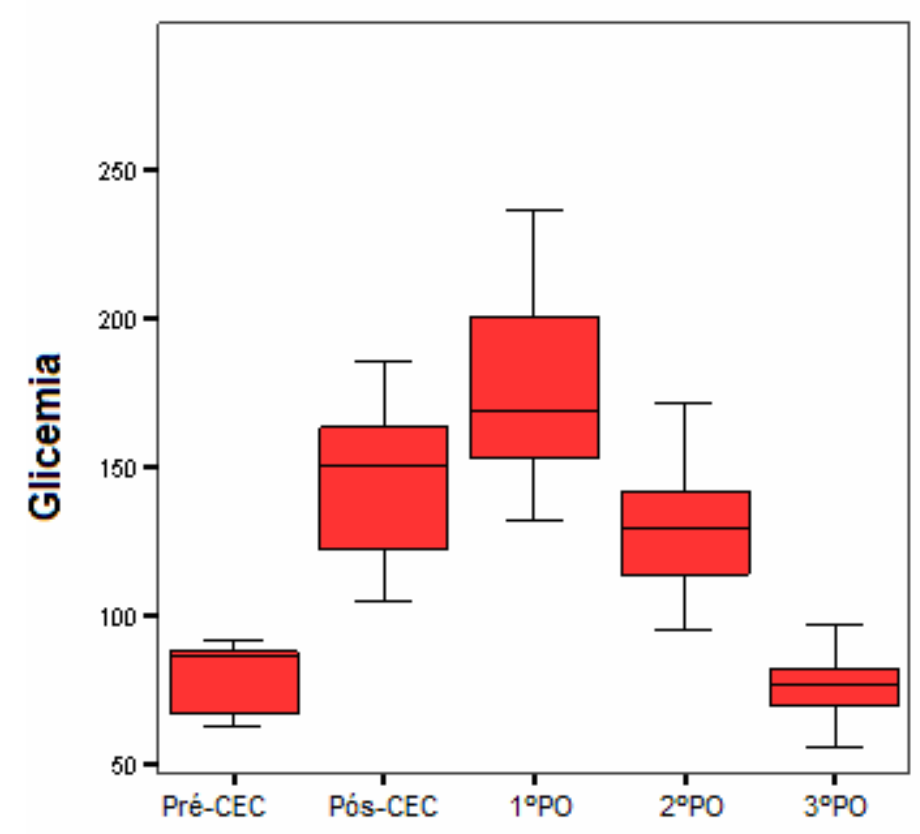

Figura 4. Cinética glicêmica. (box-plot representando a mediana dos valores, percentis 25 e 75). Valores de referência 80-110 mg/dl. 


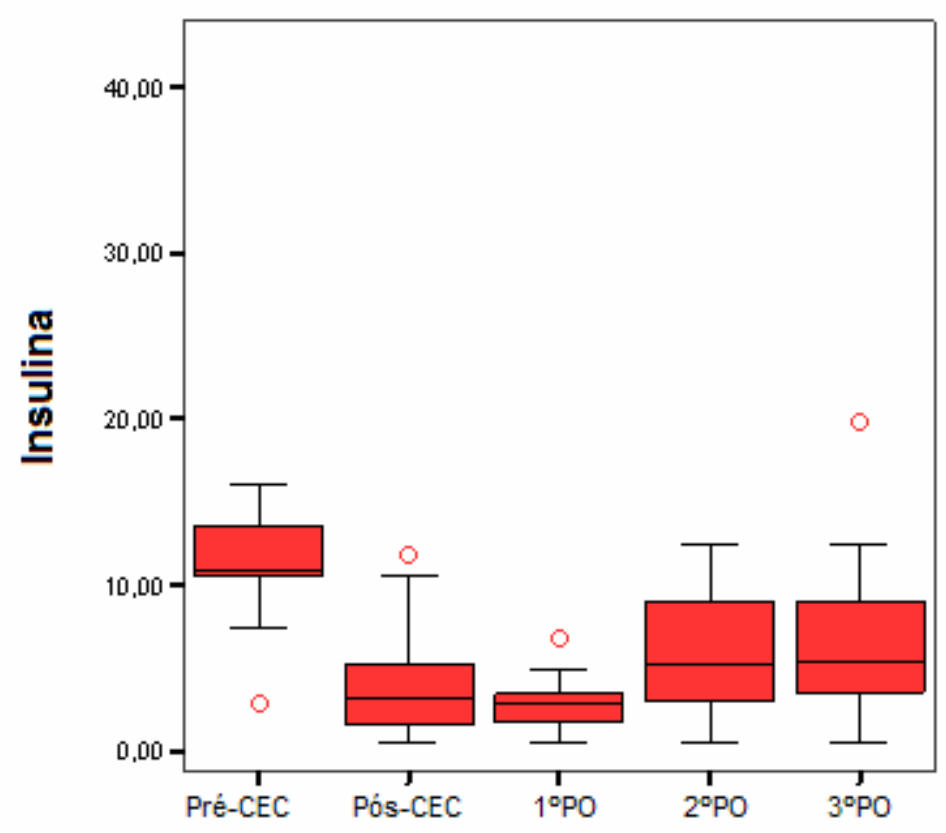

Figura 5. Cinética da insulina. (box-plot representando a mediana dos valores, percentis 25 e 75). Valores de referência 2 a $13 \mu \mathrm{U} / \mathrm{l}$.

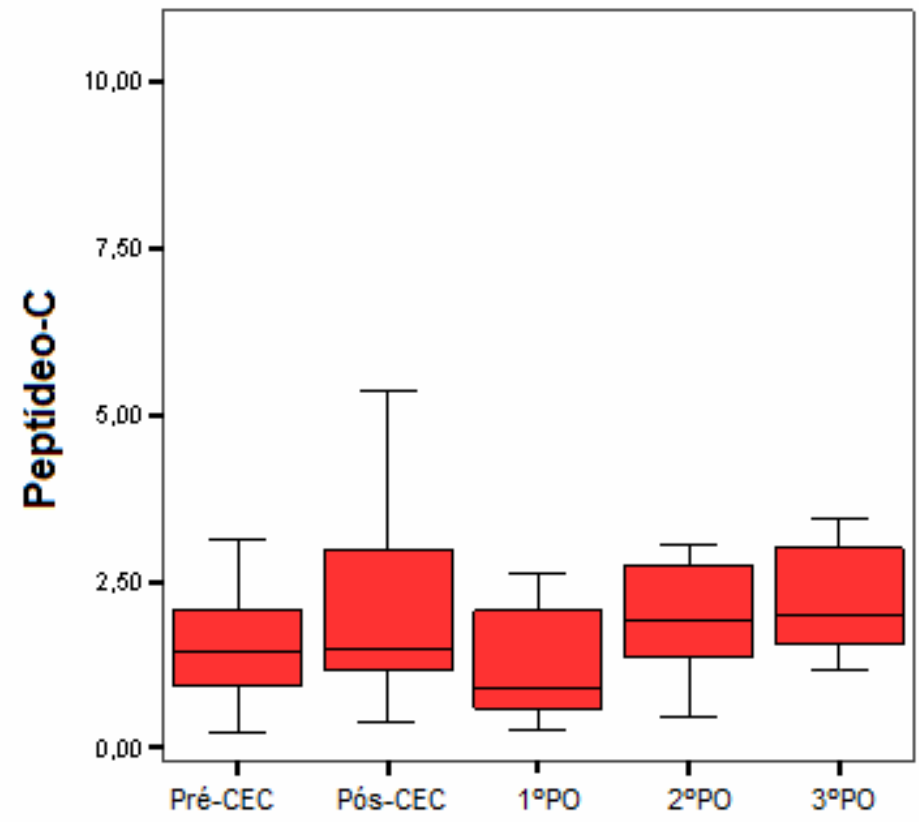

Figura 6. Cinética do peptídeo-C. (box-plot representando a mediana dos valores, percentis 25 e 75). Valores de referência $1,1-4,4$ $\mathrm{ng} / \mathrm{ml}$. 


\subsection{Cinética da adrenomedulina}

Utilizamos dois grupos controle em nosso estudo, 12 indivíduos adultos saudáveis doadores de Banco de Sangue para ratificar o valor de referência da AM indicado pelo fabricante (Tabela Anexo 2), e 10 crianças portadoras de CIA e CIV com características clínicas e cardiológicas semelhantes àquelas incluídas no grupo de estudo (Tabela Anexo 3), tendo sido coletadas amostras de sangue destas uma semana antes da cirurgia para determinar as concentrações séricas de adrenomedulina em crianças cardiopatas portadoras de CIA ou CIV com indicação de correção cirúrgica com CEC (representando os valores de adrenomedulina pré-cirúrgicos). Os resultados obtidos foram $0,35 \pm 0,14 \mathrm{ng} / \mathrm{mL}$ para os doadores de banco de sangue, e 0,38 $\pm 0,04 \mathrm{ng} / \mathrm{ml}$ (média $\pm \mathrm{SD}$ ) para as crianças cardiopatas em tempo pré-cirúrgico, corroborando os valores recomendados pela "Phoenix Pharmaceuticals" que vão até $0,5 \mathrm{ng} / \mathrm{ml}$.

Nos 20 pacientes com SRIS, a AM já se encontrava elevada no tempo pré-CEC (Tabela 3) em 17 pacientes (no tempo pré-CEC o paciente já se encontra com o tórax aberto, e em cirurgia há cerca de duas horas), tendo sofrido aumento significativo até o $1^{\circ} \mathrm{PO}$, com diferenças estatisticamente significantes quando os valores pré-CEC foram comparados ao $1^{\circ} \mathrm{PO}(\mathrm{p}=$ 0,0005). Também houve diferença estatisticamente significante quando comparamos os tempos pós-CEC versus $1^{\circ} \mathrm{PO}(p=0,0000), 1^{\circ} \mathrm{PO}$ versus $2^{\circ} \mathrm{PO}(p=0,000)$ e $1^{\circ} \mathrm{PO}$ versus $3^{\circ} \mathrm{PO}(p=0,0000)$ (Figura 7$)$. No $3^{\circ} \mathrm{PO}, 14$ crianças ainda apresentavam concentrações de adrenomedulina acima do 
intervalo de referência $(0,94 \pm 0,7 \mathrm{ng} / \mathrm{mL})$. É importante salientar que apesar de ter sofrido elevação durante o estudo (com pico no $\left.1^{\circ} \mathrm{PO}\right)$, a mediana de valores de AM encontrava-se elevada em relação aos valores de referência (até $0,5 \mathrm{ng} / \mathrm{ml}$ ) em todos os tempos estudados.

Tabela 3. Valores de adrenomedulina nos tempos do estudo (referência até $0,5 \mathrm{ng} / \mathrm{ml}$ ).

\begin{tabular}{|c|c|c|c|}
\hline & Percentil 25 & Mediana & Percentil 75 \\
\hline AM pré-CEC & 0,83 & 1,13 & 1,81 \\
\hline AM pós-CEC & 0,855 & 1,07 & 2,695 \\
\hline $\mathrm{AM} 1^{\circ} \mathrm{PO}$ & 1,825 & 3,285 & 4,255 \\
\hline $\mathrm{AM} 2^{\circ} \mathrm{PO}$ & 0,71 & 1,27 & 1,53 \\
\hline $\mathrm{AM} 3^{\circ} \mathrm{PO}$ & 0,5 & 0,915 & 1,32 \\
\hline
\end{tabular}

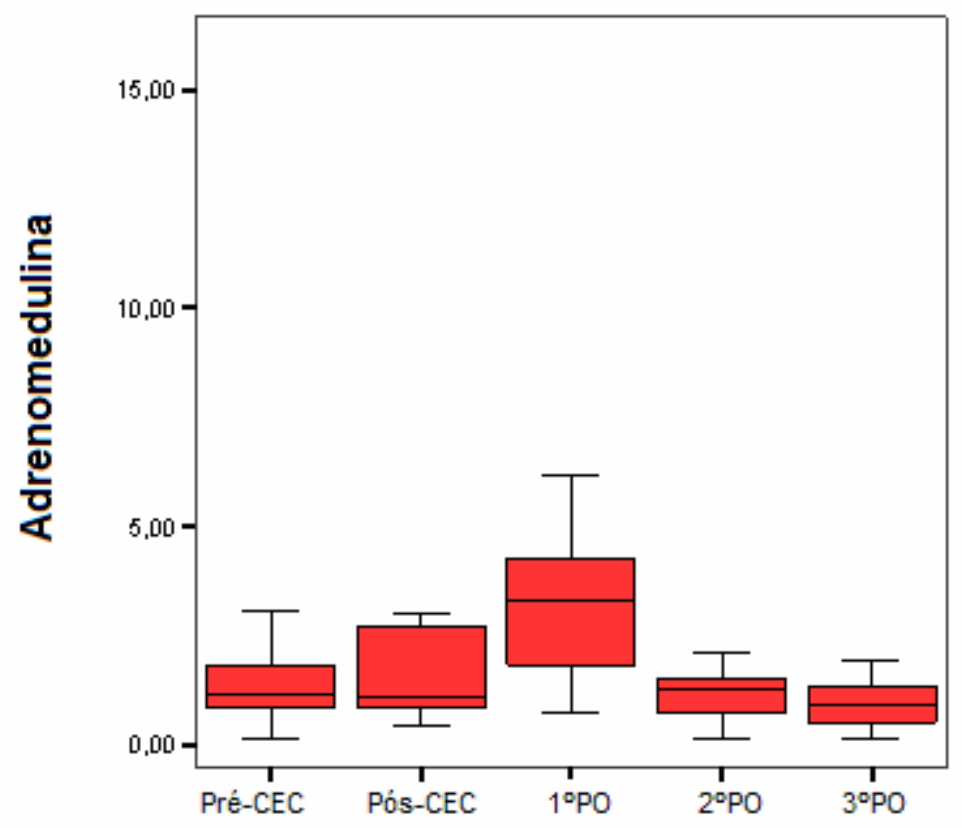

Figura 7. Cinética da adrenomedulina. (box-plot representando a mediana dos valores, percentis 25 e 75). Valores de referência até 0,5 $\mathrm{ng} / \mathrm{ml}$. 
Ainda em relação a adrenomedulina, foi observada correlação negativa significativa entre as medidas de adrenomedulina e peptídeo-C nos momentos pós-CEC $(R=-0,70, p=0,0009)$ e $1^{\circ} \mathrm{PO}(R=-0,50, p=0,0232)$ isto é, quanto maior a concentração de adrenomedulina, menor a do peptídeo-C. A relação não foi significativa nos $2^{\circ} \mathrm{PO}$ e $3^{\circ} \mathrm{PO}$.

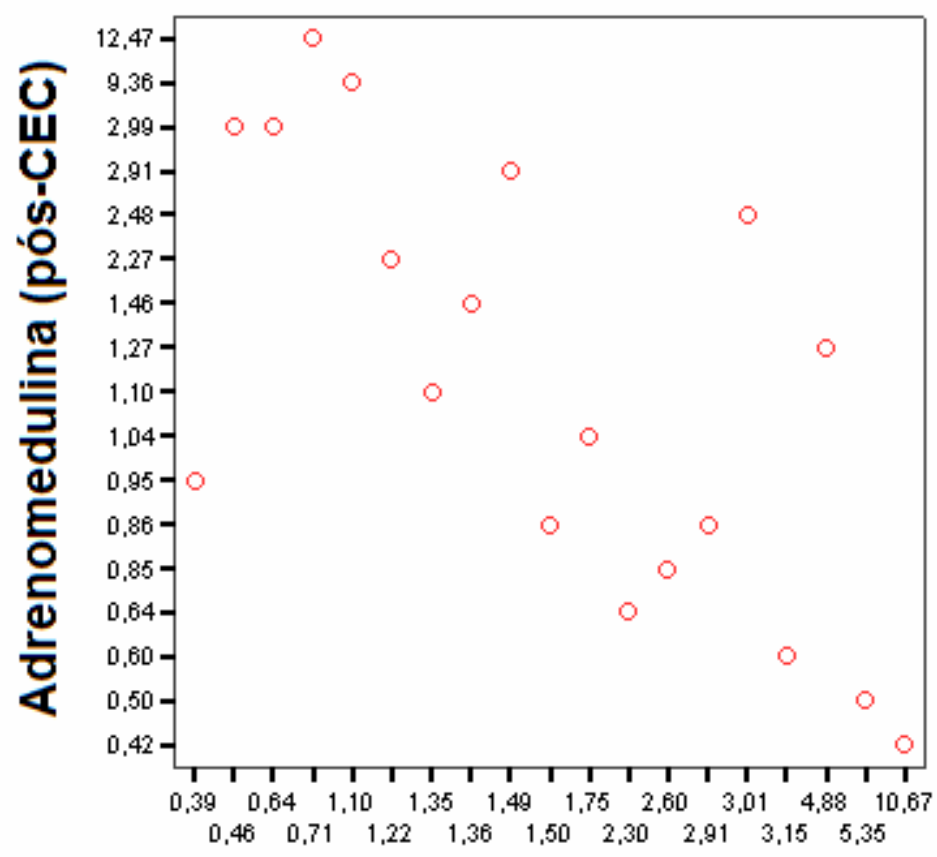

Peptídeo-C (pós-CEC)

$R=-0,70 p<0,0009$

Figura 8. Correlação entre a adrenomedulina e peptídeo-C pós-CEC. 


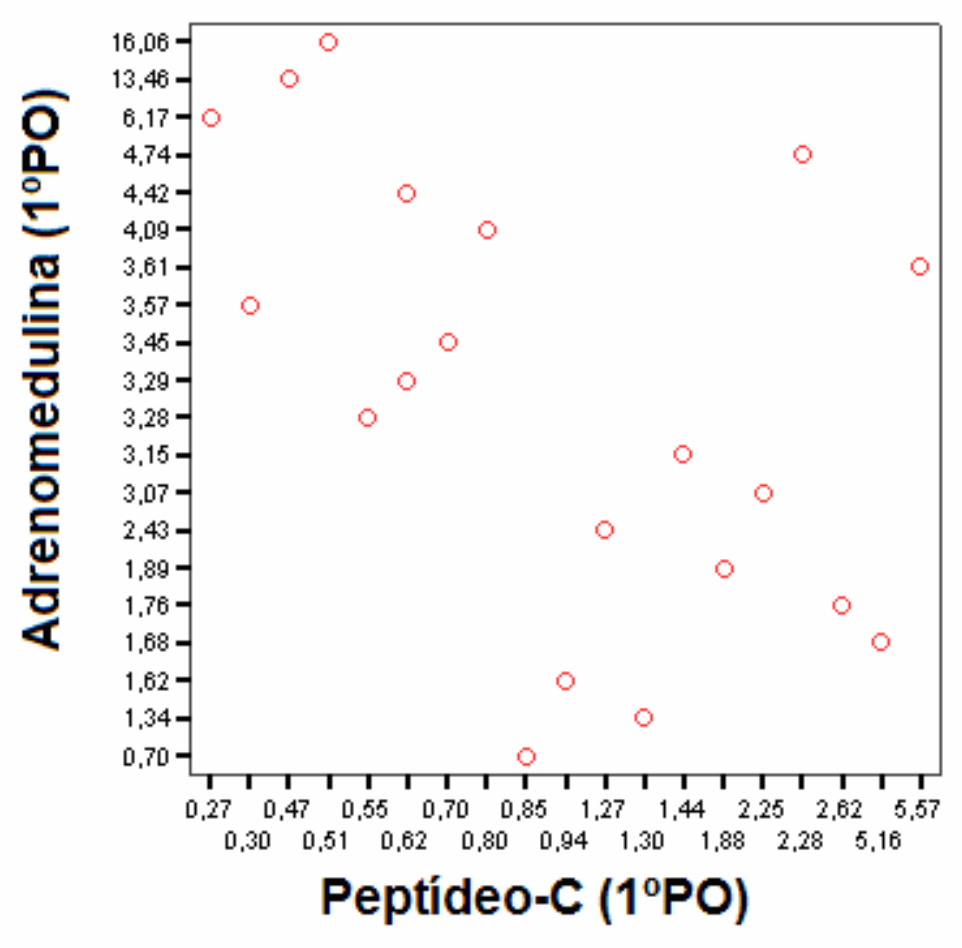

$R=-0,50 p=0,0232$

Figura 9. Correlação entre a adrenomedulina e peptídeo-C no $1^{\circ} \mathrm{PO}$.

Considerando o comportamento da adrenomedulina em relação aos hormônios estudados (ACTH e cortisol), glicemia e IL-6 entre os tempos préCEC e pós-CEC não houve associação entre a AM e os outros marcadores estudados (Tabela Anexo 4).

$\mathrm{Na}$ tentativa de se comparar o comportamento de todos os hormônios com o da adrenomedulina considerando os tempos pós-CEC e $1^{\circ} \mathrm{PO}$ foi utilizada a comparação de proporções (considerando como referência um percentual de 50\%). Não houve diferença significativa da proporção de casos com aumento ou diminuição em relação a 50\% (p-valor $=0,6422$ ) quando comparamos $\mathrm{AM}$ versus insulina, entretanto quando 
comparamos AM versus peptídeo-C houve diferença estatisticamente significante ( $p$-valor $=0,0049)$ (Figura 10), o que equivale a dizer que quando a AM se elevou, o peptídeo-C diminuiu.

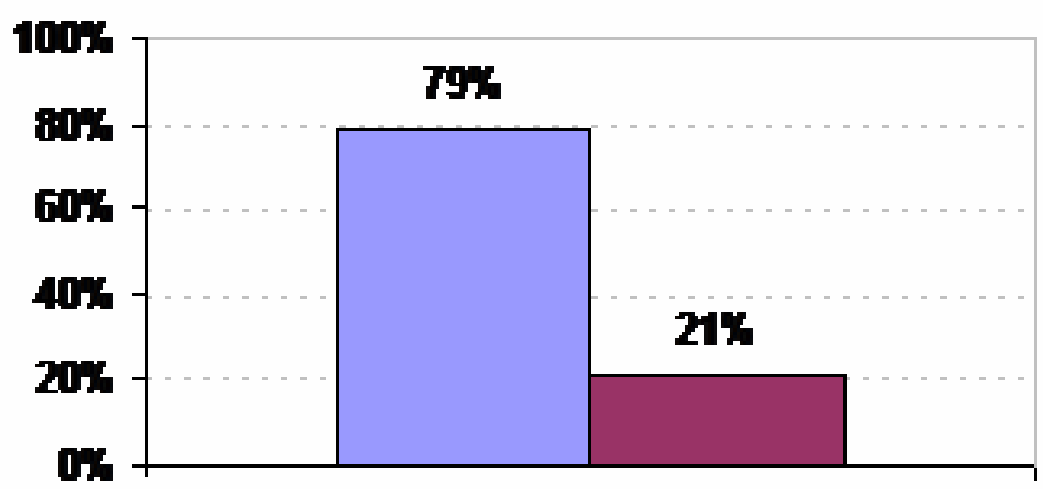

\section{Peptídeo-C}

\section{$\square \mathbf{D} \square \mathbf{A}$}

Figura 10. Proporção de pacientes que apresentaram redução do peptídeo-C do tempo pós-CEC para o $1^{\circ} \mathrm{PO}$ com elevação da adrenomedulina.

Da mesma forma, existiu diferença significativa da proporção de casos com aumento da glicemia e aumento concomitante da adrenomedulina ( $p$-valor $<0,0001)$ (Figura 11). 


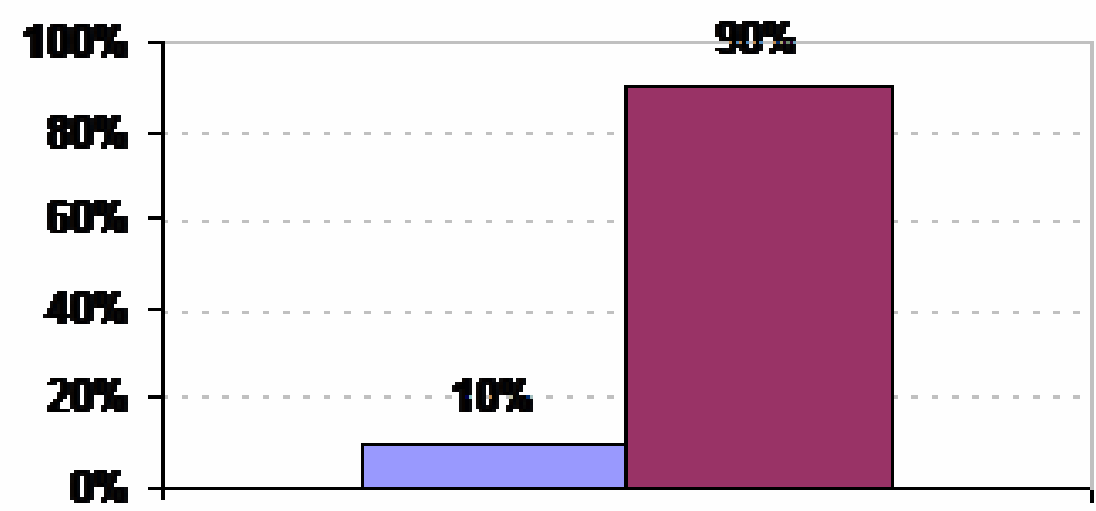

Glicemia

\section{$\square \mathbf{D} \square \mathbf{A}$}

Figura 11. Proporção de pacientes que apresentaram elevação da glicemia do tempo pós-CEC para o $1^{\circ} \mathrm{PO}$ com elevação da adrenomedulina. 


\section{DISCUSSÃO}

No presente estudo, as concentrações de glicose, insulina, peptídeo C, ACTH, cortisol, IL-6 e AM foram analisadas de maneira seriada em 20 crianças submetidas à cirurgia cardíaca com CEC como modelo de SRIS. De acordo com levantamento bibliográfico, este é o primeiro estudo pediátrico correlacionando a AM com determinações seriadas de glicose, de hormônios (insulina, peptídeo-C, cortisol, ACTH), e ainda de um marcador de resposta inflamatória, a IL-6.

Nossa pesquisa demonstrou elevação de um marcador muito estudado em pediatria nos quadros de SRIS, a IL-6, com pico no $1^{\circ} \mathrm{PO}$ mesmo considerando que a administração de corticóide possa ter influenciado a cinética da IL-6, provavelmente reduzindo a magnitude da resposta, ao menos é o resultado que se esperaria obter com a administração do corticóide no período intra-operatório (pré-CEC). Chew et al. avaliando a resposta inflamatória em crianças também descreveram níveis elevados de marcadores inflamatórios principalmente da IL-6 em crianças submetidas à CEC que receberam metilprednisolona ${ }^{33}$. Não houve diferença estatisticamente significante entre os tempos de CEC e de PA nos 
pacientes estudados, o que poderia ter influenciado o comportamento dos parâmetros laboratoriais analisados, incluindo a cinética da IL-6. Outro mecanismo proposto para a elevação de IL-6 é a hiperglicemia. Espósito et al. demonstraram este mecanismo em adultos normais e em indivíduos com intolerância a glicose após bloqueio da secreção de insulina com octreotide e utilização do método de clamp ${ }^{37}$. Wasmuth el al. em estudo prospectivo em pacientes adultos admitidos em UTI associaram a hiperglicemia com a elevação da $\mathrm{IL}-6^{41}$. Teria sido interessante estudar os pacientes em seguimento ambulatorial (representando a condição mais próxima possível do basal) Antes da internação para o procedimento cirúrgico, porém uma coleta adicional não foi possível. Entretanto, para analisar o comportamento pré-operatório de crianças com CIV e CIA e indicação de cirurgia com CEC foram analisadas 10 crianças oriundas de seguimento ambulatorial do INCOR.

No grupo de pacientes estudados não houve alterações estatisticamente significantes com relação às concentrações de $\mathrm{ACTH}$ e de cortisol, tendo o mesmo comportamento ocorrido no trabalho de Grosek et al ${ }^{88}$ em crianças que receberam corticóide previamente a CEC, e ainda no trabalho de Chambers et al ${ }^{89}$ realizado em adultos. Entretanto, Dotsch et al descreveram elevação do cortisol imediatamente após a cirurgia, com pico em 12 horas, porém a faixa etária daquele estudo ( 1 mês - 15 anos), assim como a heterogeneidade dos procedimentos (cirurgias com tempos cirúrgicos, de CEC e de PA muito díspares) pode ter influenciado os resultados ${ }^{90}$. Modan-Moses et al. ${ }^{91}$ descreveram em crianças submetidas a 
cirurgia cardíaca, elevação do cortisol e retorno a normalidade no $1^{\circ} \mathrm{PO}$. Vogeser et al. ${ }^{92}$ descreveram que essa elevação de cortisol no pósoperatório de cirurgia cardíaca com CEC se deve muito mais a diminuição da atividade da enzima 11 beta-hidroxi-esteróide desidrogenase do que a liberação reduzida de cortisol pelas adrenais. Pollock et al em estudo realizado em crianças observaram elevação discreta do cortisol e do ACTH pós-CEC, com posterior retorno aos níveis basais ${ }^{13}$. Raff et al ${ }^{93}$ descreveram que a utilização de fentanyl reduziria a liberação de ACTH hipofisário, e outros autores descreveram atenuação da resposta endócrina com utilização de fentanyl ${ }^{17}$. Weiskopf et al concluíram que a utilização de metilprednisolona estaria relacionada às baixas concentrações de cortisol encontradas nos pacientes submetidos à cirurgia cardíaca com CEC, sendo uma das explicações o efeito supressor do corticóide endovenoso no eixo hipófise-adrenal $^{94,95}$. Em nosso estudo, a associação entre a anestesia, altas doses de corticóide e a redução da atividade de 11 beta-hidroxiesteróide desidrogenase poderiam explicar $o$ não incremento das concentrações de cortisol e ACTH (se mantiveram dentro dos valores de referência).

Em relação a farmacocinética e farmacodinâmica da metilprednisolona, 10 crianças submetidas a CEC realizaram avaliação seriada da metilprednisolona sérica e após 24 horas da cirurgia, mais de $95 \%$ do corticóide já havia sido eliminado ${ }^{88}$.

Como existem inúmeras variáveis que poderiam estar direta ou indiretamente relacionadas à gênese e manutenção da hiperglicemia nos 
pacientes do presente estudo, tentamos, dentro do possível, obter um grupo homogêneo de pacientes no que se refere às características clínicas, bem como a gravidade do quadro de cardiopatia com necessidade de correção cirúrgica.

Em nosso estudo, utilizamos o valor de $110 \mathrm{mg} / \mathrm{dL}$ como valor de corte para a definição de hiperglicemia ${ }^{42}$. Todos os 20 pacientes apresentaram elevação glicêmica após a circulação extracorpórea, com pico no $1^{\circ} \mathrm{PO}$ corroborando os achados de outros autores ${ }^{15,16}$, entretanto esses trabalhos não analisaram as concentrações do peptídeo-C para estimar a reserva pancreática dos pacientes. Alguns estudos demonstraram elevação da insulina em adultos submetidos à CEC e que evoluíram com hiperglicemia, correspondendo a estado de resistência insulínica ${ }^{96,97}$. Em contrapartida, estudos pediátricos demonstram queda nos níveis de insulina, o que poderia corresponder à existência de reserva reduzida de insulina ou inibição de sua liberação ${ }^{15,97-99}$. Como observado em nosso estudo, houve inicialmente manutenção das concentrações do peptídeo-C dentro da normalidade no momento pré-CEC e pós-CEC com nadir no $1^{\circ} \mathrm{PO}$ (mediana dos valores do peptídeo-C abaixo do normal), entretanto, em nenhum momento os níveis de insulina estiveram abaixo do intervalo de referência, muito embora as comparações entre tempos de coleta tenham detectado diferenças significativas (Tabela Anexo 1). O mesmo padrão de comportamento foi observado por Bialowski et al. em crianças após CEC. Neste estudo, as concentrações do peptídeo-C foram mais fidedignas que as de insulina, sendo importante lembrar que a insulina pode ficar aderida à 
parede do circuito de $\mathrm{CEC}^{15,19}$. Vigneswaram et al. também encontraram níveis de insulina baixos após a CEC, contrariando as achados de Dotsh et al. $^{90,99}$. Smith et al. em pacientes adultos, observaram elevação da insulina imediatamente após início da CEC com redução significativa do peptídeo-C. Pela sua maior estabilidade e meia-vida mais longa, o peptídeo-C vem sendo utilizado para estimar a razão de secreção insulínica (insulin secretion rate), entretanto ainda não existem cálculos que levem em consideração que os pacientes foram submetidos à circulação extracorpórea ${ }^{100}$.

Yates et al analisaram, retrospectivamente, o prontuário de 196 crianças com menos de um ano de idade que foram submetidas à cirurgia cardíaca com CEC para avaliar se o prognóstico poderia estar associado aos valores de glicemia, e concluíram que a hiperglicemia imediatamente após a cirurgia, assim como sua manutenção estava relacionada à maior morbi-mortalidade, entretanto esses pacientes tiveram tempo de CEC mais prolongado (216 \pm 89 minutos) comparado aos sobreviventes $(158 \pm 71$ minutos $)^{43}$, e também em relação aos pacientes do presente estudo. Falcão et al. estudaram 213 crianças com hiperglicemia no pós-operatório, e esta foi relacionada à morbi-mortalidade mais elevada ${ }^{101}$. Em nosso estudo, não houve óbitos.

A maior parte dos estudos que demonstraram existência de hiperglicemia em pacientes pediátricos internados em unidades de terapia intensiva está relacionada a eventos sépticos. Sabemos que esta população apresenta resposta inflamatória diferente ${ }^{102,103}$, muito mais exuberante que os pacientes do presente estudo, portadores apenas de SRIS. 
Em adultos internados em unidades de terapia intensiva cirúrgica, Van Den Berghe et al. demonstraram que a manutenção da glicemia entre 80 e $110 \mathrm{mg} / \mathrm{dL}$ reduziu a morbi-mortalidade dos pacientes ${ }^{42}$. Van Waardenburg et al em estudo prospectivo com crianças em choque séptico $(n=10)$ e sepse por meningococo $(n=6)$ realizaram dosagens hormonais seriadas, e concluíram que a hiperglicemia estaria associada à hipoinsulinemia ${ }^{104}$, o que não foi verificado em nosso estudo uma vez que observamos, de fato, queda significativa das concentrações de insulina com o passar do tempo, porém em todos os momentos estudados os valores permaneceram dentro do intervalo de referência para o método, fazendo com que não estejamos autorizados a afirmar que os pacientes estivessem hipoinsulinêmicos. No entanto, no $1^{0} \mathrm{PO}$ a mediana dos valores de peptídeo C encontrava-se abaixo dos valores de referência, o que denota alteração da reserva pancreática de insulina.

A maioria dos pacientes deste estudo $(n=18)$ apresentou concentrações de AM elevadas no tempo pré-CEC, entretanto cabe ressaltar que os mesmos já se encontravam com tórax aberto, com aproximadamente duas horas de cirurgia quando as amostras do tempo pré-CEC foram obtidas, portanto a SRIS já havia sido desencadeada. Outro ponto importante a ser observado é que as concentrações séricas de adrenomedulina dos 10 pacientes com CIA e CIV que estavam em seguimento ambulatorial (tempo pré-operatório), encontravam-se dentro dos limites da normalidade (Tabela Anexo 3). Não houve diferença significativa quando as concentrações de AM foram confrontadas aos tempos de CEC e 
pinçamento aórtico, assim como em relação à idade, gênero e peso, resultados semelhantes aos descritos por Takeuchi et al e Komai et al ${ }^{105,106}$. Kamei et al. descreveram redução das concentrações de adrenomedulina antes da CEC e após a CEC, com valores mais elevados durante a CEC, indicando haver significativo clearance pulmonar de $A M^{107}$. Infelizmente, não pudemos realizar coleta durante a CEC, o que nos impediu de fazer comparações com esses achados. Szekely et al. concluíram que concentrações elevadas de AM presentes no pré-operatório estariam relacionadas à melhor proteção miocárdica ${ }^{108}$. Nossos resultados são semelhantes aos encontrados na literatura em trabalhos com crianças submetidas à cirurgia cardíaca com $\mathrm{CEC}^{105,106,108,109}$, no que se refere às concentrações elevadas de AM.

No presente estudo não foi observada correlação entre adrenomedulina, cortisol e ACTH, muito embora o uso de corticóide possa ter reduzido à amplitude da resposta inflamatória com repercussão no eixo hipófise-adrenal. Inibição de ACTH após infusão de AM intracerebroventricular em modelos experimentais já foi descrita ${ }^{70,} 110$. Analisando os resultados de nosso estudo, não foram encontradas correlações entre AM e insulina, entretanto, houve correlação entre AM e peptídeo-C, uma vez que incrementos de AM ocorreram simultaneamente a reduções de peptídeo- $C$ do tempo de coleta pós-CEC ao $1^{\circ} \mathrm{PO}$ (tabela X). Alguns estudos demonstraram existência de atividade inibitória direta da AM nas células beta das ilhotas pancreáticas. Sekine et al. conseguiram demonstrar exatamente onde esta inibição ocorre, isto é, nos receptores G 
da célula beta, levando a inibição da exocitose da insulina e do peptídeo C 80

Nosso estudo apresentou limitações apesar da tentativa de redução dos fatores de interferência. O número de pacientes foi restrito devido ao elevado custo das dosagens laboratoriais, uma vez que cada um dos pacientes teve sete exames laboratoriais realizados, em cinco tempos de coleta. Além disso, poderíamos ter avaliado todos os marcadores antes da indução anestésica, e também antes e após a CEC para verificar o "clearance" pulmonar de adrenomedulina. Outros testes também poderiam ter fornecido informações interessantes: dosagem de cortisol livre urinário nas primeiras $24 \mathrm{hs}$ enquanto os pacientes encontravam-se sondados, dosagem de IGF-I / IGFBP3 e hormônio de crescimento (GH) visto que também sofrem alterações nos quadros inflamatórios, porém, a realização de pesquisas em crianças traz limitações éticas relativas ao volume de sangue que pode ser obtido sem causar prejuízo aos pacientes. 
11 CONCLUSÕES

$=$ 


\section{CONCLUSÕES}

$\mathrm{Na}$ casuística estudada composta por 20 crianças com SRIS causada por cirurgia cardíaca com CEC, a existência do processo inflamatório foi confirmada pela elevação da IL-6. A adrenomedulina se encontrava elevada em todos os cinco tempos estudados com aumento concomitante da glicemia e decréscimo da insulinemia e do peptídeo-C. Tendo em vista que foi possível demonstrar a elevação da adrenomedulina em todos pacientes do presente estudo, a AM pode ter contribuído para a gênese e manutenção da hiperglicemia por meio da redução das concentrações de insulina/peptídeo-C. No entanto, apesar da elevação da $\mathrm{AM}$, não houve subseqüente elevação do $\mathrm{ACTH}$ e do cortisol, como esperávamos, porém, a administração pré-CEC de corticóide pode ter reduzido a resposta do eixo hipófise-adrenal. 
12 REFERÊNCIAS BIBLIOGRÁFICAS 


\section{REFERÊNCIAS BIBLIOGRÁFICAS}

1. Bauer J, Hentschel R, Linderkamp O. Effect of sepsis syndrome on neonatal oxygen consumption and energy expenditure. Pediatrics. 2002;110:e69.

2. Turi RA, Petros AJ, Eaton S, Fasoli L, Powis M, Basu R, et al. Energy metabolism of infants and children with systemic inflammatory response syndrome and sepsis. Ann Surg. 2001;233:581-7.

3. Van den Berghe G. Novel insights into the neuroendocrinology of critical illness. Eur J Endocrinol. 2000;143:1-13.

4. Cerra FB, Siegel JH, Coleman B, Border JR, McMenamy RR. Septic autocannibalism. A failure of exogenous nutritional support. Ann Surg. $1980 ; 192: 570-80$.

5. Michie HR. Metabolism of sepsis and multiple organ failure. World $J$ Surg. 1996;20:460-4.

6. Wang P, Li N, Li JS, Li WQ. The role of endotoxin, TNF-alpha, and IL6 in inducing the state of growth hormone insensitivity. World $J$ Gastroenterol. 2002;8:531-6.

7. Cerra FB. Metabolic manifestations of multiple systems organ failure. Crit Care Clin. 1989;5:119-31. 
8. Paparella D, Yau TM, Young E. Cardiopulmonary bypass induced inflammation: pathophysiology and treatment. An update. Eur $J$ Cardiothorac Surg. 2002;21:232-44.

9. Kirklin JK. Prospects for understanding and eliminating the deleterious effects of cardiopulmonary bypass. Ann Thorac Surg. 1991;51:529-31.

10. Chaney MA. Corticosteroids and cardiopulmonary bypass : a review of clinical investigations. Chest. 2002;121:921-31.

11. Wan S, LeClerc JL, Vincent JL. Inflammatory response to cardiopulmonary bypass: mechanisms involved and possible therapeutic strategies. Chest. 1997;112:676-92.

12. Kozik DJ, Tweddell JS. Characterizing the inflammatory response to cardiopulmonary bypass in children. Ann Thorac Surg. 2006;81:S2347-54.

13. Pollock EM, Pollock JC, Jamieson MP, Beastall GS, Wright C, Torsney B, et al. Adrenocortical hormone concentrations in children during cardiopulmonary bypass with and without pulsatile flow. $\mathrm{Br} J$ Anaesth. 1988;60:536-41.

14. Lehot JJ, Piriz H, Villard J, Cohen R, Guidollet J. Glucose homeostasis. Comparison between hypothermic and normothermic cardiopulmonary bypass. Chest. 1992;102:106-11.

15. Bialkowski J, Rubi J, Valino JM, Sanchez PA, Dominguez F, Alonso A. [Glucose metabolism in children undergoing extracorporeal circulation: its correlation with weight and the degree of hypothermia]. Rev Esp Cardiol. 1997;50:782-9.

16. Benzing G, 3rd, Francis PD, Kaplan S, Helmsworth JA, Sperling MA. Glucose and insulin changes in infants and children undergoing hypothermic open-heart surgery. Am J Cardiol. 1983;52:133-6. 
17. Winterhalter M, Brandl K, Rahe-Meyer N, Osthaus A, Hecker H, Hagl $\mathrm{C}$, et al. Endocrine stress response and inflammatory activation during CABG surgery. A randomized trial comparing remifentanil infusion to intermittent fentanyl. Eur J Anaesthesiol. 2008;25:326-35.

18. Gruber EM, Laussen PC, Casta A, Zimmerman AA, Zurakowski D, Reid $R$, et al. Stress response in infants undergoing cardiac surgery: a randomized study of fentanyl bolus, fentanyl infusion, and fentanylmidazolam infusion. Anesth Analg. 2001;92:882-90.

19. Urban K, Redford D, Larson DF. Insulin binding to the cardiopulmonary bypass biomaterials. Perfusion. 2007;22:207-10.

20. Ridgen SP, Barratt TM, Dillon MJ, De Leval M, Stark J. Acute renal failure complicating cardiopulmonary bypass surgery. Arch Dis Child. 1982;57:425-30.

21. Checchia PA, Bronicki RA, Costello JM, Nelson DP. Steroid use before pediatric cardiac operations using cardiopulmonary bypass: an international survey of 36 centers. Pediatr Crit Care Med. 2005;6:441-4.

22. Robertson-Malt S, Afrane B, El Barbary M. Prophylactic steroids for pediatric open heart surgery. Cochrane Database Syst Rev. 2007:CD005550.

23. João PRD, Junior FF. Immediate post-operative care following cardiac surgery. J Pediatr. 2003;73:S213-22.

24. Filho BG, Fantini FA, Lora HM, Martins C, Lopes RM, Hayden E, et al. Reconstrução da artéria pulmonar na operação de Jatene. Rev Bras Cir Cardiovasc 2001;16:236-43.

25. Kong AN, Jungbluth GL, Pasko MT, Beam TR, Jusko WJ. Pharmacokinetics of methylprednisolone sodium succinate and 
methylprednisolone in patients undergoing cardiopulmonary bypass. Pharmacotherapy. 1990;10:29-34.

26. Schroeder VA, Pearl JM, Schwartz SM, Shanley TP, Manning PB, Nelson DP. Combined steroid treatment for congenital heart surgery improves oxygen delivery and reduces postbypass inflammatory mediator expression. Circulation. 2003;107:2823-8.

27. Liu J, Ji B, Long C, Li C, Feng Z. Comparative effectiveness of methylprednisolone and zero-balance ultrafiltration on inflammatory response after pediatric cardiopulmonary bypass. Artif Organs. 2007;31:571-5.

28. Memoli B, Guida B, Saravo MT, Nastasi A, Trio R, Liberti R, et al. [Predictive and diagnostic factors of malnutrition in hemodialysis patients]. $G$ Ital Nefrol. 2002;19:456-66.

29. Watanabe E, Hirasawa H, Oda S, Matsuda K, Hatano M, Tokuhisa T. Extremely high interleukin-6 blood levels and outcome in the critically ill are associated with tumor necrosis factor- and interleukin-1-related gene polymorphisms. Crit Care Med. 2005;33:89-97.

30. Taniguchi T, Koido Y, Aiboshi J, Yamashita T, Suzaki S, Kurokawa A. Change in the ratio of interleukin- 6 to interleukin-10 predicts a poor outcome in patients with systemic inflammatory response syndrome. Crit Care Med. 1999;27:1262-4.

31. Abraham EJ, Minton JE. Cytokines in the hypophysis: a comparative look at interleukin-6 in the porcine anterior pituitary gland. Comp Biochem Physiol A Physiol. 1997;116:203-7.

32. Song M, Kellum JA. Interleukin-6. Crit Care Med. 2005;33:S463-5.

33. Chew MS, Brandslund I, Brix-Christensen V, Ravn HB, Hjortdal VE, Pedersen J, Hjortdal K, Hansen OK, Tønnesen E. Tissue injury and the 
inflammatory response to pediatric cardiac surgery with cardiopulmonary bypass: a descriptive study. Anesthesiology. 2001;94:745-53.

34. Matta SG, Weatherbee J, Sharp BM. A central mechanism is involved in the secretion of $\mathrm{ACTH}$ in response to IL-6 in rats: comparison to and interaction with IL-1 beta. Neuroendocrinology. 1992;56:516-25.

35. Vallieres L, Rivest S. Interleukin-6 is a needed proinflammatory cytokine in the prolonged neural activity and transcriptional activation of corticotropin-releasing factor during endotoxemia. Endocrinology. 1999;140:3890-903.

36. Beishuizen A, Thijs LG. Endotoxin and the hypothalamo-pituitaryadrenal (HPA) axis. J Endotoxin Res. 2003;9:3-24.

37. Esposito K, Nappo F, Marfella R, Giugliano G, Giugliano F, Ciotola M, et al. Inflammatory cytokine concentrations are acutely increased by hyperglycemia in humans: role of oxidative stress. Circulation. 2002;106:2067-72.

38. Tsigos C, Papanicolaou DA, Kyrou I, Defensor R, Mitsiadis CS, Chrousos GP. Dose-dependent effects of recombinant human interleukin-6 on glucose regulation. J Clin Endocrinol Metab. 1997;82:4167-70.

39. Pickup JC, Chusney GD, Thomas SM, Burt D. Plasma interleukin-6, tumour necrosis factor alpha and blood cytokine production in type 2 diabetes. Life Sci. 2000;67:291-300.

40. Pickup JC, Mattock MB, Chusney GD, Burt D. NIDDM as a disease of the innate immune system: association of acute-phase reactants and interleukin-6 with metabolic syndrome X. Diabetologia. 1997;40:1286-92.

41. Wasmuth HE, Kunz D, Graf J, Stanzel S, Purucker EA, Koch A, et al. Hyperglycemia at admission to the intensive care unit is associated with 
elevated serum concentrations of interleukin- 6 and reduced ex vivo secretion of tumor necrosis factor-alpha. Crit Care Med. 2004;32:1109-14.

42. van den Berghe $G$, Wouters $P$, Weekers F, Verwaest $C$, Bruyninckx F, Schetz $\mathrm{M}$, et al. Intensive insulin therapy in the critically ill patients. $N$ Engl $J$ Med. 2001;345:1359-67.

43. Yates AR, Dyke PC, 2nd, Taeed R, Hoffman TM, Hayes J, Feltes TF, et al. Hyperglycemia is a marker for poor outcome in the postoperative pediatric cardiac patient. Pediatr Crit Care Med. 2006;7:351-5.

44. Jakob SM, Ensinger H, Takala J. Metabolic changes after cardiac surgery. Curr Opin Clin Nutr Metab Care. 2001;4:149-55.

45. Aouifi A, Neidecker J, Vedrinne C, Bompard D, Cherfa A, Laroux MC, et al. Glucose versus lactated Ringer's solution during pediatric cardiac surgery. J Cardiothorac Vasc Anesth. 1997;11:411-4.

46. Ellis DJ, Steward DJ. Fentanyl dosage is associated with reduced blood glucose in pediatric patients after hypothermic cardiopulmonary bypass. Anesthesiology. 1990;72:812-5.

47. Bandali KS, Belanger MP, Wittnich C. Is hyperglycemia seen in children during cardiopulmonary bypass a result of hyperoxia? J Thorac Cardiovasc Surg. 2001;122:753-8.

48. Black PR, Brooks DC, Bessey $P Q$, Wolfe RR, Wilmore DW. Mechanisms of insulin resistance following injury. Ann Surg. 1982t;196:42035.

49. Dahn MS, Lange MP, Mitchell RA, Lobdell K, Wilson RF. Insulin production following injury and sepsis. J Trauma. 1987;27:1031-8. 
50. Stremmel W, Schlosser V, Koehnlein E. Effect of open-heart surgery with hemodilution perfusion upon insulin secretion. $J$ Thorac Cardiovasc Surg. 1972;64:263-71.

51. Baum D, Dillard D, Porte D. Inhibition of insulin release in infants undergoig deep hypothermic cardiovascular surgery. $N$ Engl $J$ Med. 1968;279:1-309-1.14.

52. Dandona P, Aljada A, Bandyopadhyay A. The potential therapeutic role of insulin in acute myocardial infarction in patients admitted to intensive care and in those with unspecified hyperglycemia. Diabetes Care. 2003;26:516-9.

53. Dandona P, Aljada A, Mohanty P. The anti-inflammatory and potential anti-atherogenic effect of insulin: a new paradigm. Diabetologia. 2002;45:924-30.

54. Das UN. Insulin in sepsis and septic shock. J Assoc Physicians India. 2003;51:695-700.

55. Qi YF, Shi YR, Bu DF, Jiang HF, Gao L, Pang YZ, et al. [Changes in adrenomedullin and receptor activity-modifying protein 2 mRNA in myocardium and vessels during L-NNA-induced hypertension in rats]. Sheng Li Xue Bao. 2002;54:337-41.

56. Gao F, Tao L, Yan W, Gao E, Liu HR, Lopez BL, et al. Early antiapoptosis treatment reduces myocardial infarct size after a prolonged reperfusion. Apoptosis. 2004;9:553-9.

57. Dandona P, Aljada A, Bandyopadhyay A. Inflammation: the link between insulin resistance, obesity and diabetes. Trends Immunol. 2004;25:4-7.

58. Hotamisligil GS. The role of TNFalpha and TNF receptors in obesity and insulin resistance. J Intern Med. 1999;245:621-5. 
59. Riad M, Mogos M, Thangathurai D, Lumb PD. Steroids. Curr Opin Crit Care. 2002;8:281-4.

60. Sam S, Corbridge TC, Mokhlesi B, Comellas AP, Molitch ME. Cortisol levels and mortality in severe sepsis. Clin Endocrinol (Oxf). 2004;60:29-35.

61. Modan-Moses D, Kanety H, Dagan O, Pariente C, Ben-Abraham R, Freedman L, et al. Circulating leptin levels after cardiopulmonary bypass in children. J Cardiothorac Vasc Anesth. 2001;15:740-4.

62. Kitamura K, Kangawa K, Kawamoto M, Ichiki Y, Nakamura S, Matsuo $\mathrm{H}$, et al. Adrenomedullin: a novel hypotensive peptide isolated from human pheochromocytoma. Biochem Biophys Res Commun. 1993;192:553-60.

63. Santiago JA, Garrison EA, Ventura VL, Coy DH, Bitar K, Murphy WA, et al. Synthetic human adrenomedullin and adrenomedullin 15-52 have potent short-lived vasodilator activity in the hindlimb vascular bed of the cat. Life Sci. 1994;55:PL85-90.

64. Ishimitsu T, Kojima M, Kangawa K, Hino J, Matsuoka H, Kitamura K, et al. Genomic structure of human adrenomedullin gene. Biochem Biophys Res Commun. 1994;203:631-9.

65. Sakata J, Shimokubo T, Kitamura K, Nakamura S, Kangawa K, Matsuo $\mathrm{H}$, et al. Molecular cloning and biological activities of rat adrenomedullin, a hypotensive peptide. Biochem Biophys Res Commun. 1993;195:921-7.

66. Ikeda U, Kanbe T, Kawahara Y, Yokoyama M, Shimada K. Adrenomedullin augments inducible nitric oxide synthase expression in cytokine-stimulated cardiac myocytes. Circulation. 1996;94:2560-5.

67. Hinson JP, Kapas S, Smith DM. Adrenomedullin, a multifunctional regulatory peptide. Endocr Rev. 2000;21:138-67. 
68. Elsasser TH, Kahl S, Martinez A, Montuenga LM, Pio R, Cuttitta F. Adrenomedullin binding protein in the plasma of multiple species: characterization by radioligand blotting. Endocrinology. 1999;140:4908-11.

69. Parkes DG, May CN. ACTH-suppressive and vasodilator actions of adrenomedullin in conscious sheep. J Neuroendocrinol. 1995;7:923-9.

70. Samson WK, Murphy T, Schell DA. A novel vasoactive peptide, adrenomedullin, inhibits pituitary adrenocorticotropin release. Endocrinology. 1995;136:2349-52.

71. Thomson LM, Kapas S, Carroll M, Hinson JP. Autocrine role of adrenomedullin in the human adrenal cortex. J Endocrinol. 2001;170:259-65.

72. Letizia C, Di lorio R, De Toma G, Marinoni E, Cerci S, Celi M, et al. Circulating adrenomedullin is increased in patients with corticotropindependent Cushing's syndrome due to pituitary adenoma. Metabolism. 2000;49:760-3.

73. Nagata N, Kitamura K, Kato J, Naruo H, Eto T, Takasaki M. The effect of hypothermic cardiopulmonary bypass on plasma adrenomedullin in adult cardiac surgical patients. Anesth Analg. 1997;84:1193-7.

74. Hofbauer KH, Schoof E, Kurtz A, Sandner P. Inflammatory cytokines stimulate adrenomedullin expression through nitric oxide-dependent and independent pathways. Hypertension. 2002;39:161-7.

75. Mulder H, Ahren B, Karlsson S, Sundler F. Adrenomedullin: localization in the gastrointestinal tract and effects on insulin secretion. Regul Pept. 1996;62:107-12.

76. Martinez A, Weaver C, Lopez J, Bhathena SJ, Elsasser TH, Miller MJ, et al. Regulation of insulin secretion and blood glucose metabolism by adrenomedullin. Endocrinology. 1996;137:2626-32. 
77. Hayashi M, Shimosawa T, Fujita T. Hyperglycemia increases vascular adrenomedullin expression. Biochem Biophys Res Commun. 1999;258:4536.

78. Ehlenz K, Koch B, Preuss P, Simon B, Koop I, Lang RE. High levels of circulating adrenomedullin in severe illness: correlation with C-reactive protein and evidence against the adrenal medulla as site of origin. Exp Clin Endocrinol Diabetes. 1997;105:156-62.

79. Masada K, Nagayama T, Hosokawa A, Yoshida M, Suzuki-Kusaba M, Hisa $\mathrm{H}$, et al. Effects of adrenomedullin and PAMP on adrenal catecholamine release in dogs. Am J Physiol. 1999;276:R1118-24.

80. Sekine N, Takano K, Kimata-Hayashi N, Kadowaki T, Fujita T. Adrenomedullin inhibits insulin exocytosis via pertussis toxin-sensitive $G$ protein-coupled mechanism. Am J Physiol Endocrinol Metab. 2006;291:E9E14.

81. Van den Berghe G. How does blood glucose control with insulin save lives in intensive care? J Clin Invest. 2004;114:1187-95.

82. Bondar RJ, Mead DC. Evaluation of glucose-6-phosphate dehydrogenase from Leuconostoc mesenteroides in the hexokinase method for determining glucose in serum. Clin Chem. 1974;20:586-90.

83. Neeley WE. Simple automated determination of serum or plasma glucose by a hexokinase-glucose- 6 -phosphate dehydrogenase method. Clin Chem. 1972;18:509-15.

84. Eskola JU, Nanto V, Meurling L, Lovgren TN. Direct solid-phase timeresolved immunofluorometric assay of cortisol in serum. Clin Chem. $1985 ; 31: 1731-4$. 
85. Hemmila I, Dakubu S, Mukkala VM, Siitari H, Lovgren T. Europium as a label in time-resolved immunofluorometric assays. Anal Biochem. 1984;137:335-43.

86. Soini E, Kojola H. Time-resolved fluorometer for lanthanide chelates--a new generation of nonisotopic immunoassays. Clin Chem. 1983;29:65-8.

87. Nomura I, Abe J, Noma S, Saito H, Gao B, Wheeler G, et al. Adrenomedullin Is Highly Expressed in Blood Monocytes Associated with Acute Kawasaki Disease: A Microarray Gene Expression Study. Pediatr Res. 2005;57(1):49-55. Epub 2004 Nov 5.

88. Grosek S, Ihan A, Wraber B, Gabrijelcic T, Kosin M, Osredkar J, et al. Methylprednisolone, cortisol and the cell-mediated immune response in children after ventricular septal defect repair. Clin Chem Lab Med. 2007;45:1366-72.

89. Chambers DJ, Karimzandi N, Braimbridge MV, Dunham J, Brooks F, Quiney J, et al. Hormonal and electrolyte responses during and after open heart surgery. Thorac Cardiovasc Surg. 1984;32:358-64.

90. Dotsch J, Wagner R, Groschl M, Schoof E, Harig F, Scharf J, et al. Cardiopulmonary bypass surgery does not further increase elevated serum leptin concentrations after major surgery. Pediatr Crit Care Med. 2001;2:36-9.

91. Modan-Moses D, Ehrlich S, Kanety H, Dagan O, Pariente C, Esrahi N, et al. Circulating leptin and the perioperative neuroendocrinological stress response after pediatric cardiac surgery. Crit Care Med. 2001;29:2377-82.

92. Vogeser M, Groetzner J, Kupper C, Briegel J. The serum cortisol:cortisone ratio in the postoperative acute-phase response. Horm Res. 2003;59:293-6. 
93. Raff H, Norton AJ, Flemma RJ, Findling JW. Inhibition of the adrenocorticotropin response to surgery in humans: interaction between dexamethasone and fentanyl. J Clin Endocrinol Metab. 1987;65:295-8.

94. Chow FS, Sharma A, Jusko WJ. Modeling interactions between adrenal suppression and T-helper lymphocyte trafficking during multiple dosing of methylprednisolone. J Pharmacokinet Biopharm. 1999;27:559-75.

95. Mager DE, Lin SX, Blum RA, Lates CD, Jusko WJ. Dose equivalency evaluation of major corticosteroids: pharmacokinetics and cell trafficking and cortisol dynamics. J Clin Pharmacol. 2003;43:1216-27.

96. Anderson RE, Brismar K, Barr G, Ivert T. Effects of cardiopulmonary bypass on glucose homeostasis after coronary artery bypass surgery. Eur $J$ Cardiothorac Surg. 2005;28:425-30.

97. Smith CE, Styn NR, Kalhan S, Pinchak AC, Gill IS, Kramer RP, et al. Intraoperative glucose control in diabetic and nondiabetic patients during cardiac surgery. J Cardiothorac Vasc Anesth. 2005;19:201-8.

98. Baum D, Dillard DH, Porte D, Jr. Inhibition of insulin release in infants undergoing deep hypothermic cardiovascular surgery. $N$ Engl $J$ Med. 1968;279:1309-14.

99. Vigneswaran WT, Pollock JCS, Jamieson MPG, Torsney B, Beastal $\mathrm{GH}$. Plasma levels of glucose, insulin and cortisol in children undergoing cardiac surgery: effects of pulsatile and nonpulsatile perfusion. Perfusion. 1989;4:33-9.

100. Van Cauter E, Mestrez F, Struris J, Polonsky KS. Estimation of Insulin Secretion Rates from C-peptide levels Comparison of Individual and Standard Kinetic Parameters for C-peptide Clearance. Diabetes. 1992;41:368-77. 
101. Falcao G, Ulate K, Kouzekanani K, Bielefeld MR, Morales JM, Rotta AT. Impact of Postoperative Hyperglycemia following Surgical Repair of Congenital Cardiac Defects. Pediatr Cardiol. 2008;29:628-36. Epub 2008 Jan 5 .

102. Garcia Branco R, Tasker RC, Ramos Garcia PC, Piva JP, Dias Xavier L. Glycemic control and insulin therapy in sepsis and critical illness. J Pediatr. 2007;83:S128-36.

103. Hirshberg E, Larsen G, Van Duker H. Alterations in glucose homeostasis in the pediatric intensive care unit: Hyperglycemia and glucose variability are associated with increased mortality and morbidity*. Pediatr Crit Care Med. 2008 May 19.

104. van Waardenburg DA, Jansen TC, Vos GD, Buurman WA. Hyperglycemia in children with meningococcal sepsis and septic shock: the relation between plasma levels of insulin and inflammatory mediators. J Clin Endocrinol Metab. 2006;91:3916-21.

105. Takeuchi M, Morita K, Iwasaki T, Toda Y, Oe K, Taga N, et al. Significance of adrenomedullin under cardiopulmonary bypass in children during surgery for congenital heart disease. Acta Med Okayama. 2001;55:245-52.

106. Komai H, Naito Y, Fujiwara K, Noguchi Y, Nishimura Y. Plasma adrenomedullin level after cardiopulmonary bypass. Perfusion. 1998;13:3347.

107. Kamei M, Hayashi Y, Kikumoto K, Kawai Y, Kangawa K, Kuro M, et al. Effect of cardiopulmonary bypass on pulmonary clearance of adrenomedullin in humans. Acta Anaesthesiol Scand. 2004;48:980-5. 
108. Szekely L, Vijay P, Sharp TG, Bando K, Brown JW. Correlation of plasma adrenomedullin to myocardial preservation during open-heart surgery. Pediatr Cardiol. 2000;21:228-33.

109. Florio P, Abella R, Marinoni E, Di lorio R, Letizia C, Meli M, et al. Adrenomedullin blood concentrations in infants subjected to cardiopulmonary bypass: correlation with monitoring parameters and prediction of poor neurological outcome. Clin Chem. 2008;54:202-6.

110. Shan J, Krukoff TL. Intracerebroventricular adrenomedullin stimulates the hypothalamic-pituitary-adrenal axis, the sympathetic nervous system and production of hypothalamic nitric oxide. J Neuroendocrinol. 2001;13:975-84. 
13 ANEXOS

(1) 


\section{ANEXOS}

Tabela Anexo 1. Média, desvio padrão, valor mínimo, percentil 25, mediana, percentil 75 , valor máximo.

\begin{tabular}{|c|c|c|c|c|c|c|c|c|}
\hline Variável & $\mathbf{N}$ & Média & DP & Mínimo & Percentil 25 & Mediana & $\begin{array}{c}\text { Percentil } \\
75\end{array}$ & Máximo \\
\hline Peso $(\mathrm{Kg})$ & 20 & 14,00 & $\begin{array}{l}3,77 \\
15,8\end{array}$ & 10 & 11 & 13 & 16,5 & 24 \\
\hline Idade (meses) & 20 & 38,75 & $\begin{array}{c}6 \\
13,5\end{array}$ & 12 & 29 & 35 & 49 & 84 \\
\hline CEC (minutos) & 20 & 54,10 & 0 & 35 & 45 & 51 & 63,5 & 84 \\
\hline PA (minutos) & 20 & 24,10 & 6,56 & 15 & 20 & 23 & 29 & 35 \\
\hline Insulina pré-CEC & 20 & 12,86 & 7,50 & 2,88 & 10,5 & 10,905 & 13,605 & 42,4 \\
\hline Insulina pós-CEC & 20 & 4,07 & 3,23 & 0,5 & 1,6 & 3,19 & 5,265 & 11,8 \\
\hline Insulina $1^{\circ} \mathrm{PO}$ & 20 & 2,77 & 1,50 & 0,5 & 1,685 & 2,88 & 3,46 & 6,73 \\
\hline Insulina $2^{\circ} \mathrm{PO}$ & 20 & 6,17 & 3,76 & 0,5 & 3,045 & 5,14 & 9,04 & 12,5 \\
\hline Insulina $3^{\circ} \mathrm{PO}$ & 20 & 7,38 & 6,62 & 0,5 & 3,515 & 5,37 & 9,01 & 28,9 \\
\hline Peptídeo C pré-CEC & 20 & 1,63 & 1,07 & 0,23 & 0,93 & 1,445 & 2,085 & 4,56 \\
\hline Peptídeo C pós-CEC & 19 & 2,47 & 2,42 & 0,39 & 1,1 & 1,5 & 3,01 & 10,67 \\
\hline Peptídeo C $1^{\circ} \mathrm{PO}$ & 20 & 1,52 & 1,49 & 0,27 & 0,585 & 0,895 & 2,065 & 5,57 \\
\hline Peptídeo C $2^{\circ} \mathrm{PO}$ & 19 & 2,57 & 2,02 & 0,45 & 1,31 & 1,922 & 2,74 & 7,56 \\
\hline Peptídeo C $3^{\circ} \mathrm{PO}$ & 16 & 2,58 & 1,63 & 1,19 & 1,555 & 2,005 & 2,995 & 7,2 \\
\hline & & & 11,0 & & & & & \\
\hline Glicemia pré-CEC & 20 & $\begin{array}{l}79,40 \\
144,4\end{array}$ & $\begin{array}{c}8 \\
24,3\end{array}$ & 63 & 67 & 86,5 & 88 & 92 \\
\hline Glicemia pós-CEC & 20 & $\begin{array}{c}5 \\
179,9\end{array}$ & $\begin{array}{c}8 \\
39,6\end{array}$ & 105 & 122,5 & 150,5 & 163,5 & 186 \\
\hline Glicemia $1^{\circ} \mathrm{PO}$ & 20 & $\begin{array}{c}5 \\
130,6\end{array}$ & $\begin{array}{c}1 \\
19,4\end{array}$ & 132 & 153,5 & 169 & 201 & 290 \\
\hline Glicemia $2^{\circ} \mathrm{PO}$ & 20 & 0 & $\begin{array}{c}1 \\
10,1\end{array}$ & 95 & 114 & 129,5 & 142 & 172 \\
\hline Glicemia $3^{\circ} \mathrm{PO}$ & 20 & 76,70 & 4 & 56 & 70 & 76,5 & 82 & 97 \\
\hline AM pré-CEC & 20 & 1,32 & 0,74 & 0,13 & 0,83 & 1,13 & 1,81 & 3,05 \\
\hline AM pós-CEC & 20 & 2,35 & 3,09 & 0,42 & 0,855 & 1,07 & 2,695 & 12,47 \\
\hline AM $1^{\circ} \mathrm{PO}$ & 20 & 4,19 & 3,87 & 0,7 & 1,825 & 3,285 & 4,255 & 16,06 \\
\hline AM $2^{\circ} \mathrm{PO}$ & 20 & 1,56 & 1,91 & 0,14 & 0,71 & 1,27 & 1,53 & 9,36 \\
\hline AM $3^{\circ} \mathrm{PO}$ & 20 & 0,94 & 0,48 & 0,13 & 0,5 & 0,915 & 1,32 & 1,92 \\
\hline ACTH pré-CEC & 20 & 31,30 & $\begin{array}{c}12,0 \\
5 \\
10,1\end{array}$ & 10 & 25,5 & 31 & 38,5 & 57 \\
\hline ACTH pós-CEC & 20 & 26,10 & 2 & 9 & 19 & 26,5 & 33,5 & 44 \\
\hline АCTH $1^{\circ} \mathrm{PO}$ & 20 & 27,05 & 8,15 & 12 & 23 & 27 & 33,5 & 41 \\
\hline АCTH $2^{\circ} \mathrm{PO}$ & 20 & 28,70 & 7,32 & 16 & 25 & 28 & 33,5 & 47 \\
\hline АСТH $3^{\circ} \mathrm{PO}$ & 20 & 27,50 & 8,56 & 15 & 19,5 & 26 & 33,5 & 44 \\
\hline Cortisol pré-CEC & 20 & 17,36 & 8,51 & 5,71 & 13,915 & 15,445 & 19,47 & 39 \\
\hline Cortisol pós-CEC & 20 & 16,40 & 8,80 & 4,43 & 10,615 & 15,57 & 19,855 & 40,29 \\
\hline Cortisol 10PO & 20 & 13,66 & 6,75 & 3,64 & 10,555 & 12,405 & 15,915 & 37,38 \\
\hline Cortisol $2^{\circ} \mathrm{PO}$ & 20 & 18,27 & 4,95 & 11,76 & 14,455 & 17,605 & 21,74 & 28,73 \\
\hline Cortisol $3^{\circ} \mathrm{PO}$ & 20 & 17,79 & 6,03 & 8,39 & 13,6 & 17,45 & 22,32 & 28,2 \\
\hline IL-6 pré-CEC & 20 & 8,31 & 5,97 & 1,82 & 2,45 & 7,85 & 12,655 & 21,5 \\
\hline IL-6 pós-CEC & 20 & 13,22 & 5,11 & 1,85 & 12,065 & 13,84 & 16,125 & 20,52 \\
\hline IL-6 $1^{\circ} \mathrm{PO}$ & 20 & 15,45 & 6,03 & 6,03 & 13,21 & 14,215 & 16,375 & 36,5 \\
\hline IL-6 $2^{\circ} \mathrm{PO}$ & 20 & 10,36 & 6,92 & 1,79 & 2,175 & 12,7 & 16,87 & 19,57 \\
\hline IL-6 $3^{\circ} \mathrm{PO}$ & 20 & 5,13 & 8,63 & 0,03 & 1,83 & 1,885 & 2,625 & 36,03 \\
\hline
\end{tabular}


Tabela Anexo 2. Grupo de indivíduos doadores sadios do banco de sangue.

\begin{tabular}{ccc}
\hline & Nome (sigla) & $\begin{array}{c}\text { Concentração AM } \\
\mathrm{ng} / \mathrm{mL}\end{array}$ \\
\hline C1 & ASJ & 0,40 \\
C2 & ANB & 0,53 \\
C3 & AP & 0,58 \\
C4 & DAA & 0,29 \\
C5 & DRA & 0,54 \\
C6 & EMO & 0,31 \\
C7 & ERS & 0,35 \\
C8 & DSP & 0,32 \\
C9 & FTM & 0,23 \\
C10 & GFS & 0,11 \\
C11 & GNR & 0,26 \\
C12 & JLVF & 0,32 \\
& Mediana & 0,32 \\
& Mínimo & 0,11 \\
& Máximo & 0,58 \\
\hline
\end{tabular}


Tabela Anexo 3. Crianças com cardiopatia congênita (CIA ou CIV) com quadro clínico semelhante àquelas incluídas no estudo, uma semana antes da cirurgia eletiva com CEC (corresponde aos valores pré-operatórios). Colocar a mediana, valor mínimo e máximo de AM.

\begin{tabular}{cccc}
\hline & Nome & Doença & $\begin{array}{c}\text { Concentração AM } \\
n g / m L\end{array}$ \\
\hline 1 & MCL & CIA & 0,31 \\
2 & RS & CIV & 0,43 \\
3 & RS & CIV & 0,40 \\
4 & ASC & CIA & 0,40 \\
5 & GD & CIV & 0,37 \\
6 & KHM & CIA & 0,42 \\
7 & RJA & CIA & 0,37 \\
8 & MSFH & CIA & 0,38 \\
9 & YFJ & CIV & 0,39 \\
10 & SRJ & CIV & 0,32 \\
& & Mediana & 0,38 \\
& & Mínimo & 0,31 \\
& & Máximo & 0,43 \\
\hline
\end{tabular}


Tabelas Anexo 4. Testes estatísticos utilizados

\section{ADRENOMEDULINA VS TIPO DE CIRURGIA}

\begin{tabular}{|l|cccccc|}
\hline Cirurgia & N & Média & DP & Mínimo & Mediana & Máximo \\
\hline CIA & 11 & 1,28 & 0,86 & 0,13 & 1,22 & 3,05 \\
CIV & 9 & 1,37 & 0,61 & 0,82 & 1,07 & 2,54 \\
\hline Total & 20 & 1,32 & 0,74 & 0,13 & 1,13 & 3,05 \\
\hline \multicolumn{7}{|c}{0,909} \\
Teste de Mann-Whitney: $p$-valor $=3$ \\
\hline
\end{tabular}

\section{ADRENOMEDULINA VS GÊNERO}

\begin{tabular}{|l|cccccc|}
\hline \multicolumn{1}{|c|}{ Sexo } & $\mathbf{N}$ & Média & DP & Mínimo & Mediana & Máximo \\
\hline F & 11 & 1,35 & 0,86 & 0,13 & 1,07 & 3,05 \\
M & 9 & 1,27 & 0,60 & 0,62 & 1,19 & 2,54 \\
\hline Total & 20 & 1,32 & 0,74 & 0,13 & 1,13 & 3,05 \\
\hline \multicolumn{7}{|c}{0,732} \\
Teste de Mann-Whitney: p-valor $=4$ \\
\hline
\end{tabular}

ADRENOMEDULINA VS IDADE

\begin{tabular}{|c|c|}
\cline { 2 - 2 } \multicolumn{1}{c|}{} & Idade vs AM Pré \\
\hline $\mathbf{R}$ & $-0,02$ \\
$\mathbf{p}$-valor & 0,9247 \\
$\mathbf{N}$ & 20 \\
\hline $\mathbf{R}=$ Coeficiente de correlação de \\
Spearman
\end{tabular}

ADRENOMEDULINA VS TEMPOS DE COLETA

\begin{tabular}{|c|c|c|}
\cline { 2 - 3 } \multicolumn{1}{c|}{} & CEC vs (AM Pós - AM Pré) & PA vs (AM Pós - AM Pré) \\
\hline $\mathbf{R}$ & $-0,36$ & 0,03 \\
p-valor & 0,1233 & 0,8918 \\
$\mathbf{N}$ & 20 & 20 \\
\hline
\end{tabular}

$\mathbf{R}=$ Coeficiente de correlação de Spearman 
ADRENOMEDULINA VS INSULINA

\begin{tabular}{|c|c|c|c|c|c|c|}
\hline & & AM pre & AM pos & AM 1 & AM 2 & AM 3 \\
\hline \multirow{3}{*}{ Insulina pré } & $\mathbf{R}$ & $-0,09$ & $-0,15$ & $-0,28$ & $-0,11$ & $-0,19$ \\
\hline & $p$-valor & 0,7159 & 0,5311 & 0,2330 & 0,6482 & 0,4255 \\
\hline & $\mathbf{N}$ & 20 & 20 & 20 & 20 & 20 \\
\hline \multirow{3}{*}{ Insulina pós } & $\mathbf{R}$ & 0,40 & 0,05 & 0,09 & 0,00 & 0,04 \\
\hline & $p$-valor & 0,0818 & 0,8427 & 0,7146 & 0,9900 & 0,8750 \\
\hline & $\mathbf{N}$ & 20 & 20 & 20 & 20 & 20 \\
\hline \multirow{3}{*}{ Insulina 1} & $\mathbf{R}$ & $-0,21$ & 0,33 & 0,32 & 0,11 & 0,09 \\
\hline & $p$-valor & 0,3695 & 0,1620 & 0,1686 & 0,6314 & 0,7005 \\
\hline & $\mathrm{N}$ & 20 & 20 & 20 & 20 & 20 \\
\hline \multirow{3}{*}{ Insulina 2} & $\mathbf{R}$ & 0,36 & 0,09 & 0,11 & 0,05 & 0,09 \\
\hline & $p$-valor & 0,1163 & 0,6909 & 0,6359 & 0,8207 & 0,6958 \\
\hline & $\mathbf{N}$ & 20 & 20 & 20 & 20 & 20 \\
\hline \multirow{3}{*}{ Insulina 3} & $\mathbf{R}$ & $-0,10$ & $-0,01$ & $-0,04$ & $-0,16$ & 0,05 \\
\hline & p-valor & 0,6633 & 0,9724 & 0,8650 & 0,4939 & 0,8354 \\
\hline & $\mathbf{N}$ & 20 & 20 & 20 & 20 & 20 \\
\hline
\end{tabular}

ADRENOMEDULINA VS PEPTÍDEO C

\begin{tabular}{|c|c|c|c|c|c|c|}
\hline & & AM pre & AM pos & AM 1 & AM 2 & AM 3 \\
\hline \multirow{4}{*}{ Pept C pré } & $\mathbf{R}$ & 0,49 & 0,51 & 0,40 & 0,32 & 0,52 \\
\cline { 2 - 7 } & $\mathbf{p}$-valor & 0,0278 & 0,0217 & 0,0822 & 0,1704 & 0,0190 \\
\cline { 2 - 7 } & $\mathbf{N}$ & 20 & 20 & 20 & 20 & 20 \\
\hline \multirow{3}{*}{ Pept C pós } & $\mathbf{R}$ & $-0,21$ & $\mathbf{- 0 , 7 0}$ & $-0,56$ & $-0,23$ & $-0,25$ \\
\cline { 2 - 7 } & p-valor & 0,3870 & $\mathbf{0 , 0 0 0 9}$ & 0,0131 & 0,3401 & 0,3002 \\
\cline { 2 - 7 } & $\mathbf{N}$ & 19 & $\mathbf{1 9}$ & 19 & 19 & 19 \\
\hline \multirow{3}{*}{ Pept C 10 } & $\mathbf{R}$ & $-0,31$ & $-0,43$ & $-\mathbf{0 , 5 0}$ & $-0,56$ & $-0,26$ \\
\cline { 2 - 7 } & $\mathbf{p}$-valor & 0,1792 & 0,0559 & $\mathbf{0 , 0 2 3 2}$ & 0,0097 & 0,2664 \\
\cline { 2 - 7 } & $\mathbf{N}$ & 20 & 20 & $\mathbf{2 0}$ & 20 & 20 \\
\hline \multirow{3}{*}{ Pept C 2 } & $\mathbf{R}$ & $-0,33$ & $-0,28$ & $-0,19$ & 0,11 & 0,11 \\
\cline { 2 - 7 } & $\mathbf{p}$-valor & 0,1631 & 0,2535 & 0,4243 & 0,6576 & 0,6524 \\
\cline { 2 - 7 } & $\mathbf{N}$ & 19 & 19 & 19 & 19 & 19 \\
\hline \multirow{3}{*}{ Pept C 3 } & $\mathbf{R}$ & $-0,32$ & $-0,47$ & $-0,62$ & $-0,21$ & $-0,04$ \\
\cline { 2 - 7 } & $\mathbf{p}$-valor & 0,2306 & 0,0646 & 0,0103 & 0,4377 & 0,8711 \\
\cline { 2 - 7 } & $\mathbf{N}$ & 16 & 16 & 16 & 16 & 16 \\
\hline
\end{tabular}

R = Coeficiente de correlação de Spearman 


\section{ADRENOMEDULINA VS GLICEMIA}

\begin{tabular}{|c|c|c|c|c|c|c|}
\hline & & & & & & \\
\hline & AM pre & AM pos & AM 1 & AM 2 & AM 3 \\
\hline \multirow{3}{*}{$\begin{array}{c}\text { Glicemia } \\
\text { (mg/dL) pré- } \\
\text { CEC }\end{array}$} & $\mathbf{R}$ & $-0,13$ & 0,01 & $-0,20$ & $-0,37$ & $-0,10$ \\
\hline & $p$-valor & 0,5898 & 0,9723 & 0,3997 & 0,1062 & 0,6854 \\
\hline & $\mathbf{N}$ & 20 & 20 & 20 & 20 & 20 \\
\hline \multirow{3}{*}{$\begin{array}{l}\text { Glicemia pós- } \\
\text { CEC }\end{array}$} & $\mathbf{R}$ & $-0,18$ & $-0,12$ & $-0,25$ & $-0,34$ & 0,15 \\
\hline & $p$-valor & 0,4405 & 0,6052 & 0,2824 & 0,1453 & 0,5414 \\
\hline & $\mathbf{N}$ & 20 & 20 & 20 & 20 & 20 \\
\hline \multirow{3}{*}{ Glicemia $1^{\circ} \mathrm{PO}$} & $\mathbf{R}$ & 0,25 & 0,15 & 0,09 & $-0,09$ & 0,23 \\
\hline & $p$-valor & 0,2915 & 0,5286 & 0,6958 & 0,6958 & 0,3195 \\
\hline & $\mathrm{N}$ & 20 & 20 & 20 & 20 & 20 \\
\hline \multirow{3}{*}{ Glicemia $2^{\circ} \mathrm{PO}$} & $\mathbf{R}$ & 0,04 & $-0,05$ & 0,07 & $-0,04$ & 0,25 \\
\hline & p-valor & 0,8576 & 0,8328 & 0,7623 & 0,8625 & 0,2913 \\
\hline & $\mathrm{N}$ & 20 & 20 & 20 & 20 & 20 \\
\hline \multirow{3}{*}{ Glicemia $3^{\circ} \mathrm{PO}$} & $\mathbf{R}$ & $-0,07$ & 0,38 & 0,52 & 0,08 & 0,19 \\
\hline & $p$-valor & 0,7573 & 0,0995 & $\underline{0,0200}$ & 0,7525 & 0,4326 \\
\hline & N & 20 & 20 & 20 & 20 & 20 \\
\hline
\end{tabular}

\section{ADRENOMEDULINA VS ACTH}

\begin{tabular}{|c|c|c|c|c|c|c|}
\hline & & AM pre & AM pos & AM 1 & AM 2 & AM 3 \\
\hline \multirow{3}{*}{$\begin{array}{c}\text { ACTH }(\mathrm{pg} / \mathrm{mL}) \\
\text { pré-CEC }\end{array}$} & $\mathbf{R}$ & $-0,18$ & 0,16 & 0,25 & 0,25 & $-0,11$ \\
\hline & p-valor & 0,4414 & 0,4965 & 0,2917 & 0,2798 & 0,6328 \\
\hline & $\mathbf{N}$ & 20 & 20 & 20 & 20 & 20 \\
\hline \multirow{3}{*}{$\begin{array}{l}\text { ACTH pós } \\
\text { CEC }\end{array}$} & $\mathbf{R}$ & $-0,25$ & 0,07 & 0,22 & 0,24 & $-0,01$ \\
\hline & p-valor & 0,2927 & 0,7801 & 0,3605 & 0,3003 & 0,9548 \\
\hline & $\mathbf{N}$ & 20 & 20 & 20 & 20 & 20 \\
\hline \multirow{3}{*}{ ACTH $1^{\circ} \mathrm{PO}$} & $\mathbf{R}$ & $-0,27$ & 0,09 & 0,09 & 0,12 & $-0,30$ \\
\hline & $p$-valor & 0,2534 & 0,6992 & 0,7207 & 0,6188 & 0,2041 \\
\hline & N & 20 & 20 & 20 & 20 & 20 \\
\hline \multirow{3}{*}{ ACTH $2^{\circ} \mathrm{PO}$} & $\mathbf{R}$ & $-0,21$ & 0,01 & $-0,09$ & 0,27 & 0,01 \\
\hline & p-valor & 0,3847 & 0,9558 & 0,7062 & 0,2501 & 0,9798 \\
\hline & N & 20 & 20 & 20 & 20 & 20 \\
\hline \multirow{3}{*}{ АCTH $3^{\circ} \mathrm{PO}$} & $\mathbf{R}$ & $-0,02$ & 0,23 & 0,26 & 0,39 & 0,05 \\
\hline & p-valor & 0,9396 & 0,3206 & 0,2634 & 0,0932 & 0,8472 \\
\hline & $\mathrm{N}$ & 20 & 20 & 20 & 20 & 20 \\
\hline
\end{tabular}




\section{ADRENOMEDULINA VS CORTISOL}

\begin{tabular}{|c|c|c|c|c|c|c|}
\hline & & AM pre & AM pos & AM 1 & AM 2 & AM 3 \\
\hline \multirow{3}{*}{$\begin{array}{c}\text { Cortisol } \\
\text { (mcg/dL) pré- } \\
\text { CEC }\end{array}$} & $\mathbf{R}$ & 0,08 & $-0,02$ & 0,00 & 0,44 & 0,13 \\
\hline & $p$-valor & 0,7527 & 0,9373 & 1,0000 & 0,0546 & 0,5869 \\
\hline & $\mathrm{N}$ & 20 & 20 & 20 & 20 & 20 \\
\hline \multirow{3}{*}{$\begin{array}{l}\text { Cortisol pós- } \\
\text { CEC }\end{array}$} & $\mathbf{R}$ & 0,12 & 0,02 & 0,16 & 0,18 & 0,39 \\
\hline & $p$-valor & 0,6224 & 0,9197 & 0,4939 & 0,4465 & 0,0870 \\
\hline & $\mathrm{N}$ & 20 & 20 & 20 & 20 & 20 \\
\hline \multirow{3}{*}{ Cortisol $1^{\circ} \mathrm{PO}$} & $\mathbf{R}$ & 0,37 & 0,16 & 0,09 & 0,34 & 0,49 \\
\hline & $p$-valor & 0,1069 & 0,5079 & 0,7052 & 0,1426 & 0,052 \\
\hline & $\mathbf{N}$ & 20 & 20 & 20 & 20 & 20 \\
\hline \multirow{3}{*}{ Cortisol $2^{\circ} \mathrm{PO}$} & $\mathbf{R}$ & 0,09 & 0,04 & 0,09 & 0,06 & 0,40 \\
\hline & $p$-valor & 0,6958 & 0,8774 & 0,7146 & 0,8060 & 0,0844 \\
\hline & $\mathbf{N}$ & 20 & 20 & 20 & 20 & 20 \\
\hline \multirow{3}{*}{ Cortisol $3^{\circ} \mathrm{PO}$} & $\mathbf{R}$ & $-0,33$ & $-0,04$ & $-0,02$ & 0,14 & 0,01 \\
\hline & $p$-valor & 0,1582 & 0,8674 & 0,9298 & 0,5522 & 0,9548 \\
\hline & $\mathrm{N}$ & 20 & 20 & 20 & 20 & 20 \\
\hline
\end{tabular}

R = Coeficiente de correlação de Spearman

ADRENOMEDULINA VS IL-6

\begin{tabular}{|c|c|c|c|c|c|c|}
\hline & & AM pre & AM pos & AM 1 & AM 2 & AM 3 \\
\hline \multirow{3}{*}{ IL-6 pre } & $\mathbf{R}$ & $-0,07$ & $-0,25$ & $-0,38$ & 0,00 & 0,03 \\
\hline & $p$-valor & 0,7598 & 0,2930 & 0,0942 & 0,9900 & 0,8898 \\
\hline & $\mathrm{N}$ & 20 & 20 & 20 & 20 & 20 \\
\hline \multirow{3}{*}{ IL-6 pos } & $\mathbf{R}$ & $-0,28$ & $-0,19$ & $-0,23$ & 0,13 & $-0,20$ \\
\hline & $p$-valor & 0,2350 & 0,4252 & 0,3357 & 0,5738 & 0,4052 \\
\hline & $\mathbf{N}$ & 20 & 20 & 20 & 20 & 20 \\
\hline \multirow{3}{*}{ IL-6 1Po } & $\mathbf{R}$ & 0,07 & $-0,41$ & $-0,57$ & $-0,18$ & $-0,15$ \\
\hline & $p$-valor & 0,7672 & 0,0725 & 0,0091 & 0,4465 & 0,5185 \\
\hline & $\mathbf{N}$ & 20 & 20 & 20 & 20 & 20 \\
\hline \multirow{3}{*}{ IL-6 2PO } & $\mathbf{R}$ & $-0,05$ & $-0,12$ & $-0,22$ & 0,15 & 0,06 \\
\hline & $p$-valor & 0,8256 & 0,5998 & 0,3523 & 0,5269 & 0,8011 \\
\hline & $\mathbf{N}$ & 20 & 20 & 20 & 20 & 20 \\
\hline \multirow{3}{*}{ IL-6 3po } & $\mathbf{R}$ & $-0,01$ & $-0,03$ & $-0,11$ & 0,00 & $-0,14$ \\
\hline & $p$-valor & 0,9799 & 0,9108 & 0,6534 & 0,9899 & 0,5470 \\
\hline & $\mathbf{N}$ & 20 & 20 & 20 & 20 & 20 \\
\hline
\end{tabular}




\section{ADRENOMEDULINA}

\begin{tabular}{|c|c|}
\hline Fator & p-valor \\
\hline Tempo & $\underline{\mathbf{0 , 0 0 5}}$ \\
\hline
\end{tabular}

\begin{tabular}{|c|c|}
\hline Comparação entre tempos & p-valor* \\
\hline Pré vs Pós & 1,0000 \\
${\text { Pré vs } 1^{\circ} \text { dia }}^{*}$ & $\underline{\mathbf{0 , 0 0 0 5}}$ \\
${\text { Pré vs } 2^{\circ} \text { dia }}^{1,0000}$ \\
${\text { Pré vs } 3^{\circ} \text { dia }}^{\circ}$ & 0,7206 \\
\hline${\text { Pós vs } 1^{\circ} \text { dia }}^{\text {Pós vs } 2^{\circ} \text { dia }}$ & $\underline{\mathbf{0 , 0 0 0 0}}$ \\
\hline Pósvs $^{\circ}$ dia & 1,0000 \\
$1^{\circ}$ dia vs $2^{\circ}$ dia & $\underline{0,1595}$ \\
$1^{\circ}$ dia vs $3^{\circ}$ dia & $\underline{\mathbf{0 , 0 0 0 0 0}}$ \\
\hline $2^{\circ}$ dia vs $3^{\circ}$ dia & 0,3829 \\
\hline
\end{tabular}

INSULINA

\begin{tabular}{|c|c|}
\hline Fator & p-valor \\
\hline Tempo & $\underline{\mathbf{0 , 0 0 5}}$ \\
\hline
\end{tabular}

\begin{tabular}{|c|c|}
\hline Comparação entre tempos & $\mathbf{p}$-valor* \\
\hline Pré vs Pós $^{*}$ & $\underline{\mathbf{0 , 0 0 0 0}}$ \\
${\text { Pré vs } 1^{\circ} \text { dia }}^{\mathbf{0 , 0 0 0 0}}$ & $\underline{\mathbf{0 , 0 0 2 6}}$ \\
${\text { Pré vs } 2^{\circ} \text { dia }}^{\text {Pré vs } 3^{\circ} \text { dia }}$ & $\underline{\mathbf{0 , 0 0 5 3}}$ \\
\hline${\text { Pós vs } 1^{\circ} \text { dia }}^{\circ}$ & 1,0000 \\
${\text { Pós vs } 2^{\circ} \text { dia }}^{\text {Pós vs } 3^{\circ} \text { dia }}$ & 0,1612 \\
\hline $1^{\circ}$ dia vs $2^{\circ}$ dia & 0,2875 \\
\hline $1^{\circ}$ dia vs $3^{\circ}$ dia & $\underline{\mathbf{0 , 0 0 5 6}}$ \\
\hline $2^{\circ}$ dia vs $3^{\circ}$ dia & $\underline{\mathbf{0 , 0 0 0 4}}$ \\
\hline
\end{tabular}




\begin{tabular}{|c|c|}
\hline Fator & p-valor \\
\hline Tempo & $\underline{\mathbf{0 , 0 0 5}}$ \\
\hline
\end{tabular}

GLICEMIA

\begin{tabular}{|c|c|}
\hline Comparação entre tempos & $\mathbf{p}$-valor* \\
\hline Pré vs Pós & $\underline{\mathbf{0 , 0 0 0 0}}$ \\
${\text { Pré vs } 1^{\circ} \text { dia }}^{*}$ & $\underline{\mathbf{0 , 0 0 0 0}}$ \\
${\text { Pré vs } 2^{\circ} \text { dia }}^{\mathbf{0 , 0 0 0 0}}$ \\
${\text { Pré vs } 3^{\circ} \text { dia }}^{1,0000}$ \\
\hline${\text { Pós vs } 1^{\circ} \text { dia }}^{\text {Pós vs } 2^{\circ} \text { dia }}$ & $\underline{\mathbf{0 , 0 0 4 6}}$ \\
${\text { Pós vs } 3^{\circ} \text { dia }}^{\circ}$ & $\underline{\mathbf{0 , 0 0 0 0}}$ \\
\hline $1^{\circ}$ dia vs $2^{\circ}$ dia & $\underline{\mathbf{0 , 0 0 0 0}}$ \\
$1^{\circ}$ dia vs $3^{\circ}$ dia & $\underline{\mathbf{0 , 0 0 0 0}}$ \\
\hline $2^{\circ}$ dia vs $3^{\circ}$ dia & $\underline{\mathbf{0 , 0 0 0 0}}$ \\
\hline
\end{tabular}

\begin{tabular}{|c|c|}
\hline Fator & p-valor \\
\hline Tempo & $\underline{\mathbf{0 , 0 0 5}}$ \\
\hline
\end{tabular}

\section{IL-6}

\begin{tabular}{|c|c|}
\hline Comparação entre tempos & p-valor* \\
\hline Pré vs Pós & 0,1754 \\
${\text { Pré vs } 1^{\circ} \text { dia }}^{*}$ & $\underline{\mathbf{0 , 0 0 0 9}}$ \\
${\text { Pré vs } 2^{\circ} \text { dia }}^{1,0000}$ \\
${\text { Pré vs } 3^{\circ} \text { dia }}^{\circ}$ & 0,2953 \\
\hline${\text { Pós vs } 1^{\circ} \text { dia }}^{\text {Pós vs } 2^{\circ} \text { dia }}$ & 1,0000 \\
${\text { Pós vs } 3^{\circ} \text { dia }}^{\circ}$ & 1,0000 \\
$1^{\circ}$ dia vs $2^{\circ}$ dia & $\underline{0,0001}$ \\
$1^{\circ}$ dia vs $3^{\circ}$ dia & $\underline{0,0000}$ \\
\hline $2^{\circ}$ dia vs $3^{\circ}$ dia & $\underline{\mathbf{0 , 0 0 2 0}}$ \\
\hline
\end{tabular}

\section{ADRENOMEDULINA VS INSULINA (PRÉ E PÓS- CEC)}

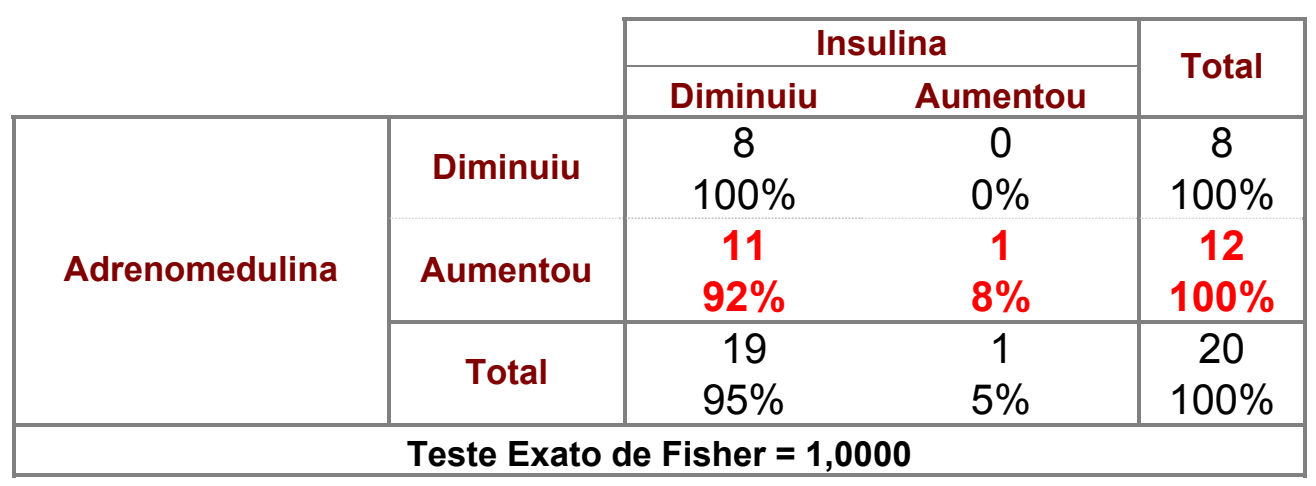


ADRENOMEDULINA VS PEPTÍDEO C (PRÉ E PÓS -CEC)

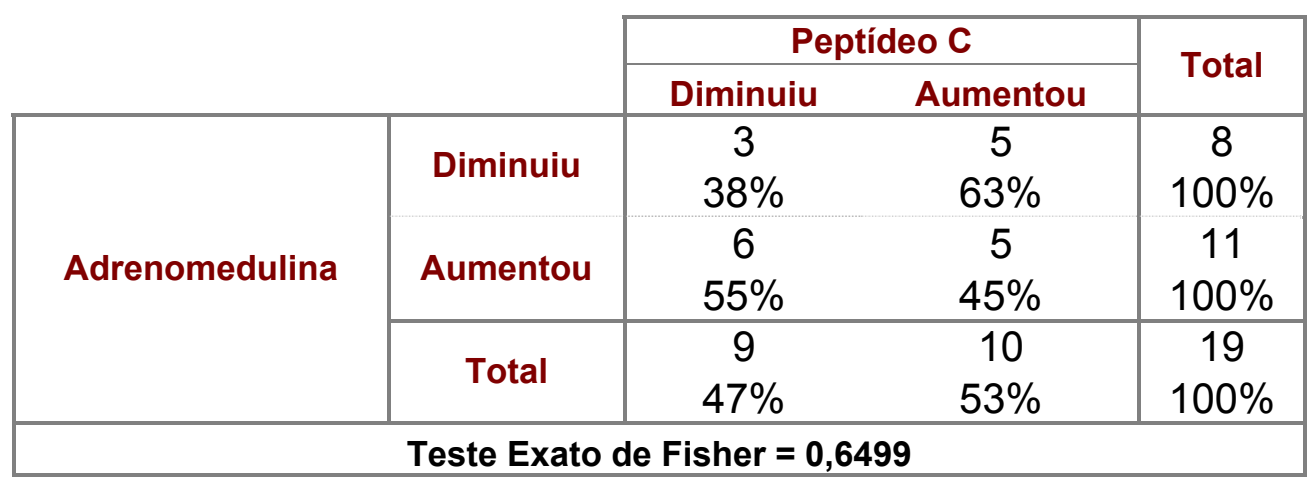

ADRENOMEDULINA VS ACTH (PRÉ E PÓS- CEC)

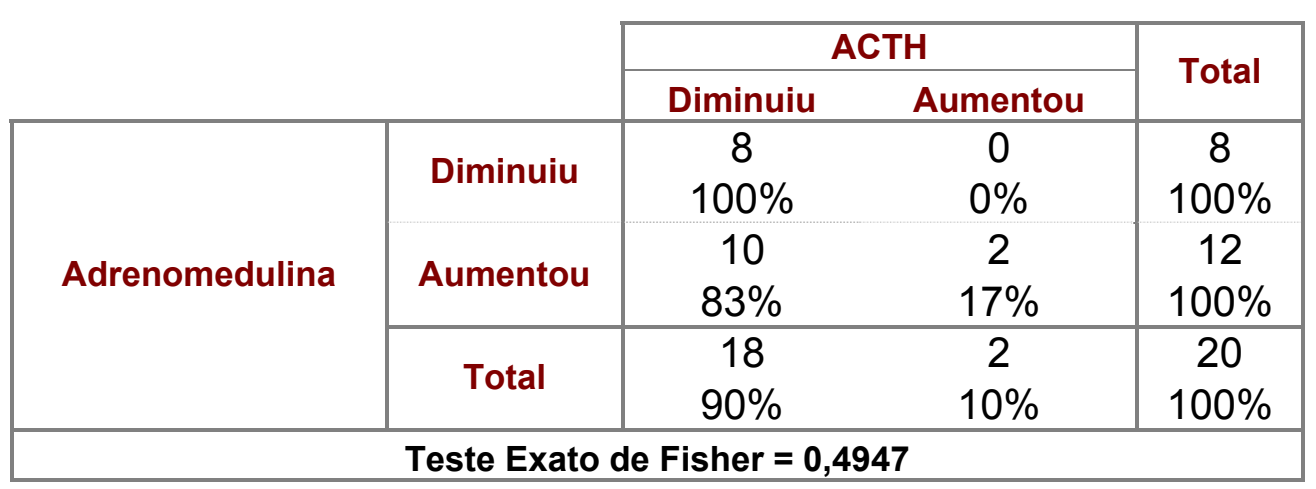

ADRENOMEDULINA VS CORTISOL (PRÉ E PÓS- CEC)

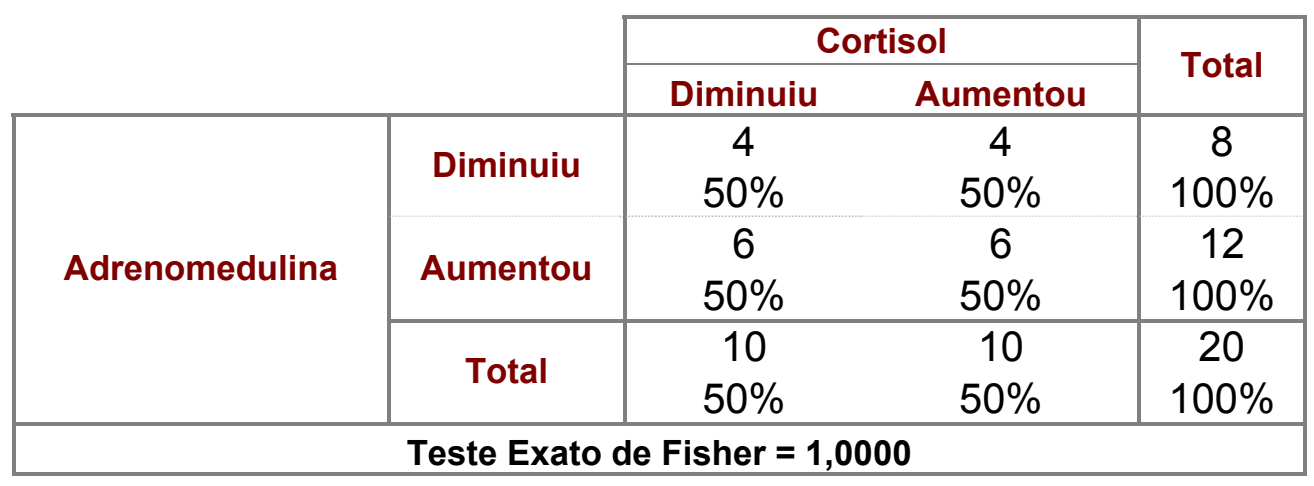


ADRENOMEDULINA VS IL-6 (PRÉ E PÓS -CEC)

\begin{tabular}{|c|c|c|c|c|}
\hline & & \multicolumn{2}{|c|}{ IL-6 } & \multirow{2}{*}{ Total } \\
\hline & & Diminuiu & Aumentou & \\
\hline \multirow{3}{*}{ Adrenomedulina } & Diminuiu & $\begin{array}{c}2 \\
25 \%\end{array}$ & $\begin{array}{c}6 \\
75 \%\end{array}$ & $\begin{array}{c}8 \\
100 \%\end{array}$ \\
\hline & Aumentou & $\begin{array}{c}3 \\
25 \%\end{array}$ & $\begin{array}{c}9 \\
75 \%\end{array}$ & $\begin{array}{c}12 \\
100 \%\end{array}$ \\
\hline & Total & $\begin{array}{c}5 \\
25 \%\end{array}$ & $\begin{array}{c}15 \\
75 \%\end{array}$ & $\begin{array}{c}20 \\
100 \%\end{array}$ \\
\hline \multicolumn{5}{|c|}{ Teste Exato de Fisher $=1,0000$} \\
\hline
\end{tabular}

ADRENOMEDULINA VS INSULINA (PÓS- CEC E 1PO)

\begin{tabular}{|c|c|c|c|c|}
\hline Adrenomedulina & Insulina & $\mathbf{N}$ & $\%$ & IC de 95\% \\
\hline \multirow{3}{*}{ Aumentou } & Diminuiu & 11 & $58 \%$ & {$[35,7 \% ; 80,1 \%]$} \\
& Aumentou & 8 & $42 \%$ & {$[19,9 \% ; 64,3 \%]$} \\
\cline { 2 - 5 } & Total & 19 & $100 \%$ & - \\
\hline
\end{tabular}

ADRENOMEDULINA VS PEPTÍDEO C (PÓS- CEC E 1O)

\begin{tabular}{|c|c|c|c|c|}
\hline Adrenomedulina & Peptídeo C & N & $\%$ & IC de 95\% \\
\hline \multirow{3}{*}{ Aumentou } & Diminuiu & 15 & $79 \%$ & {$[60,6 \% ; 97,3 \%]$} \\
& Aumentou & 4 & $21 \%$ & {$[2,7 \% ; 39,4 \%]$} \\
\cline { 2 - 5 } & Total & 19 & $100 \%$ & - \\
\hline
\end{tabular}

ADRENOMEDULINA VS GLICEMIA (PÓS- CEC E 1PO)

\begin{tabular}{|c|c|c|c|c|}
\hline Adrenomedulina & Glicemia & N & $\%$ & IC de 95\% \\
\hline \multirow{3}{*}{ Aumentou } & Diminuiu & 2 & $10 \%$ & {$[0 \% ; 23,1 \%]$} \\
& & & & {$[76,9 \% ;$} \\
& Aumentou & 18 & $90 \%$ & $103,1 \%]$ \\
\cline { 2 - 5 } & Total & 20 & $100 \%$ & - \\
\hline
\end{tabular}

ADRENOMEDULINA VS ACTH (PÓS -CEC E 1PO)

\begin{tabular}{|c|c|c|c|c|}
\hline Adrenomedulina & ACTH & N & $\%$ & IC de 95\% \\
\hline \multirow{3}{*}{ Aumentou } & Diminuiu & 8 & $42 \%$ & {$[19,9 \% ; 64,3 \%]$} \\
& Aumentou & 11 & $58 \%$ & {$[35,7 \% ; 80,1 \%]$} \\
\cline { 2 - 5 } & Total & 19 & $100 \%$ & - \\
\hline
\end{tabular}


ADRENOMEDULINA VS CORTISOL (PÓS -CEC E 1PO)

\begin{tabular}{|c|c|c|c|c|}
\hline Adrenomedulina & Cortisol & $\mathbf{N}$ & $\%$ & IC de 95\% \\
\hline \multirow{3}{*}{ Aumentou } & Diminuiu & 10 & $50 \%$ & {$[28,1 \% ; 71,9 \%]$} \\
& Aumentou & 10 & $50 \%$ & {$[28,1 \% ; 71,9 \%]$} \\
\cline { 2 - 5 } & Total & 20 & $100 \%$ & - \\
\hline
\end{tabular}

ADRENOMEDULINA VS IL-6 (PÓS- CEC E 1O)

\begin{tabular}{|c|c|c|c|c|}
\hline Adrenomedulina & IL-6 & N & $\%$ & IC de 95\% \\
\hline \multirow{3}{*}{ Aumentou } & Diminuiu & 8 & $40 \%$ & {$[18,5 \% ; 61,5 \%]$} \\
& Aumentou & 12 & $60 \%$ & {$[38,5 \% ; 81,5 \%]$} \\
\cline { 2 - 5 } & Total & 20 & $100 \%$ & - \\
\hline
\end{tabular}




\section{Anexo 5}

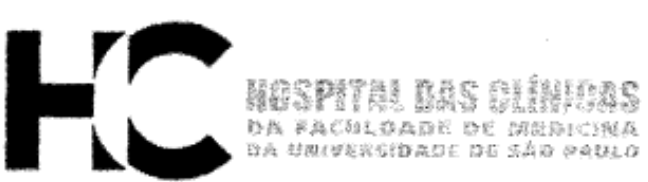

\section{APROVAÇÃO}

A Comissão de Ética para Análise de Projetos de Pesquisa - CAPPesq da Diretoria Clínica do Hospital das Clínicas e da Faculdade de Medicina da Universidade de São Paulo, em sessão de 09.11.05, APROVOU o Protocolo de Pesquisa $n^{\circ}$ 675/05, intitulado: "Importância da adrenomedulina no eixo hipófise-adrenal e na cinética glicêmica de pacientes pediátricos com Síndrome da Resposta Inflamatória Sistêmica" apresentado pela COMISSÃO CIENTÍFICA DO INSTITUTO DO CORAÇÃO, inclusive o Termo de Consentimento Livre e Esclarecido.

$$
\text { Cabe ao pesquisador elaborar e apresentar à }
$$
CAPPesq, os relatórios parciais e final sobre a pesquisa (Resolução do Conselho Nacional de Saúde n 196, de 10.10.1996, inciso IX. 2, letra "c")

Pesquisador(a) Responsável: Dra. Thelma Suely Okay Pesquisador (a) Executante: Dr. Ronaldo Arkader

CAPPesq, 09 de Novembro de 2005.

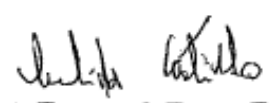

PROF. DR. EUCLIDES AYRES DE CASTILHO

Presidente da Comissão de Ética para Análise de Projetos de Pesquisa 


\section{Anexo 6}

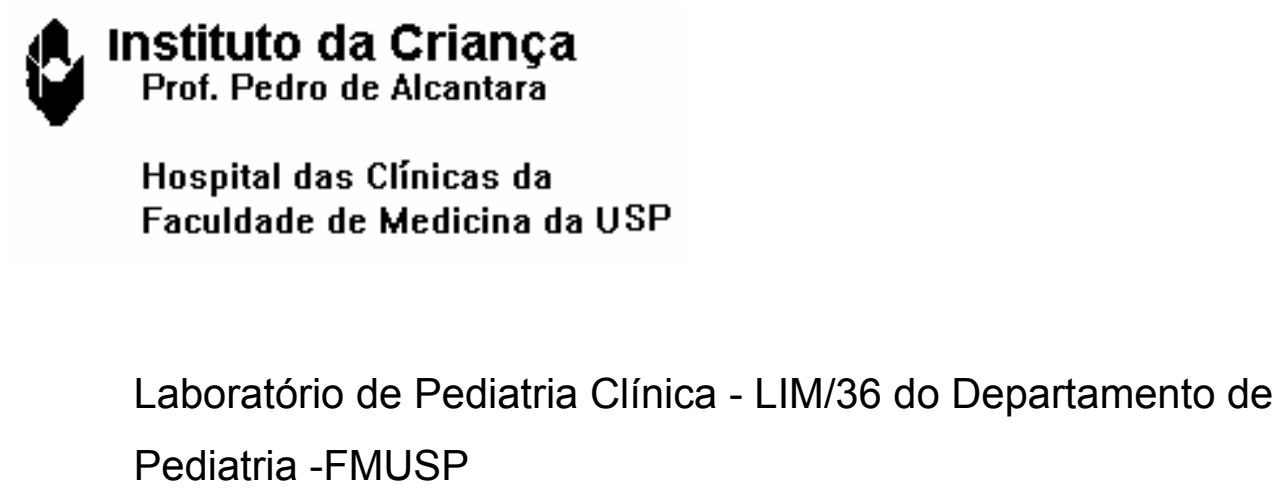

Pediatria -FMUSP

Título da Pesquisa: Importância da adrenomedulina no eixo hipófiseadrenal e na cinética glicêmica de pacientes pediátricos com síndrome da resposta inflamatória sistêmica

\section{TERMO DE CONSENTIMENTO LIVRE E ESCLARECIDO}

As crianças que tem problemas no coração e precisam ser operadas, ficam muito tempo sem comer, recebendo apenas soros. A cirurgia causa inflamação no corpo todo da criança, e elas ficam com a taxa de açúcar no sangue alta. Os médicos tratam esta taxa alta de açúcar no sangue alta com insulina, mas ninguém sabe se este problema tem a ver com alguns hormônios que a gente normalmente não dosa em crianças que fazem cirurgia do coração.

Este é o motivo que nos faz pedir para que o (a) senhor (a) autorize seu filho a participar desta pesquisa para que a gente possa dosar a quantidade destes hormônios no sangue de seu filho. Precisaremos fazer isto 5 vezes: a primeira antes da cirurgia, a segunda logo após o final da cirurgia, depois mais três vezes nos três dias seguintes. A gente pretende aproveitar uma hora que estiverem colhendo sangue do seu filho para fazer 
controles da cirurgia para colher o sangue para a pesquisa sem precisar picar o seu filho de novo. Se a nossa idéia estiver certa de que alguns hormônios é que causam esta taxa alta de açúcar no sangue, vai dar para tratar as crianças com os remédios certos, nas doses certas, ou até, talvez, evitar que as crianças fiquem com a taxa de açúcar alta no sangue. Assim, a gente espera ajudar as crianças a recuperarem mais rápido. A gente vai informar os resultados dos exames para o (a) senhor (senhora), e uma cópia será colocada no prontuário médico de seu filho.

É por este motivo que solicitamos que o sr (sra) nos autorize a colher $8 \mathrm{ml}$ de sangue do seu filho (filha), cinco vezes. Como nós aproveitaremos um dia que ele (ela) tiver que colher os exames normais que costumam fazer após cirurgia, não haverá necessidade de levar outra picada de agulha, e os riscos são os de uma colheita de sangue de uma veia do braço, por exemplo, dor da picada, formação de alguma marca roxa. Os resultados dos exames serão mantidos em sigilo (o nome do seu filho (filha) jamais será mencionado). O sr (sra) deve estar ciente que sua participação é voluntária, portanto não receberá qualquer tipo de pagamento ou indenização. Caso não queira participar deste estudo, o tratamento de seu filho (filha) não sofrerá qualquer tipo de alteração ou prejuízo. Caso o sr. (sra) tenha alguma dúvida, favor entrar em contato com o médico responsável pelo Laboratório de Pediatria Clínica (LIM/36 do Departamento de Pediatria da FMUSP).

- Dra Thelma Suely Okay - CRM 51.478

- Laboratório do Instituto da Criança - Av. Dr. Enéas Carvalho de Aguiar, 647

- 50 andar CEP- 05403-900 Cerqueira César São Paulo-SP.

Após a leitura deste documento, sinto-me devidamente informado a respeito do que será feito com o sangue de meu filho (filha), e estou de acordo em participar. 
Nome do

paciente:

RG (INCOR):

Data de nascimento

Endereço

Residencial:

Nome do

Responsável:

Assinatura do

responsável:

São Paulo, de de 200 